\title{
Carbon Nanofibres and Nanotubes for Composite Applications
}

\author{
Maria C. Paiva and José A. Covas
}

\begin{abstract}
Carbon nanotubes and nanofibers are now commercially viable making possible a number of effective applications. This chapter provides a brief but didactic revision of the polymer/nanotube or nanofiber mixing methods, with major focus on melt mixing. The nanotube or nanofiber dispersion parameters are discussed, as well as the role of chemical functionalization. As a framework for this discussion the general properties of carbon nanotubes and nanofibers, as well as their polymer composites, are summarized. A market perspective is presented demonstrating the growing interest of these materials. The effective market growth will depend on the efficiency in tackling dominant factors such as price, material quality/purity and consistency, health and safety aspects and, especially in the case of polymer nanocomposites, dispersibility and compatibility with the matrix.
\end{abstract}

\section{Introduction}

The seminal work of Ijima [33] brought carbon nanotubes to the attention of both the scientific community and society. The unique mechanical, thermal and electrical properties of these materials rapidly triggered a wide scope of anticipated advanced technical applications, often with a prospective outstanding societal impact.

In particular, as comprehensively presented by Coleman et al. [20], early theoretical and experimental work on carbon nanotubes (CNT) and nanocomposites production and characterization carried out between the late 1990s and the middle of the 2000s revealed the potential of CNT as reinforcement material. The potential of these nanoparticles for electrical and thermal conductivity was demonstrated, whilst the main requirements for effective mechanical reinforcement were identified

M.C. Paiva $(\bowtie) \cdot$ J.A. Covas

Institute for Polymers and Composites/i3N, University of Minho, Guimarães, Portugal

e-mail: mcpaiva@dep.uminho.pt

J.A. Covas

e-mail: jcovas@dep.uminho.pt

(C) Springer Science+Business Media Singapore 2016

S. Rana and R. Fangueiro (eds.), Fibrous and Textile Materials

for Composite Applications, Textile Science and Clothing Technology,

DOI 10.1007/978-981-10-0234-2_7 
to be the large CNT aspect ratio, their good dispersion in the matrix and the efficient polymer-reinforcement interfacial stress transfer. High interfacial shear stress associated with the large interfacial contact area of the CNTs were expected to improve the capacity for energy dissipation, and thus to induce a large toughness enhancement of the nanocomposites (Wichmann et al. [96]). Suhr and Koratkar [86] reported an increase in loss modulus in the order of $1000 \%$ for polycarbonate (PC) composites with $2 \mathrm{wt} \%$ of single wall carbon nanotubes (SWNT), confirming this ability. The improvement in composite properties was observed to vary with the processing technique, but also with the type of polymer matrix, emphasizing the role of interfacial energy and polymer morphology. Carponcin et al. [15] reported large variations of the electrical percolation with CNT content for composites prepared by melt mixing, depending on the polymer matrix. While for amorphous thermoplastics the percolation was reported near $0.3 \mathrm{wt} \% \mathrm{CNT}$, for semi-crystalline polymers it ranged from 0.9 to $2.5 \mathrm{wt} \% \mathrm{CNT}$.

While CNT were subjected to intense research (often supported by relatively abundant programs put up by funding agencies), a few manufacturers launched their grades and more and more applications were envisaged (some of these were near to visionary, such as an elevator to space, or the global replacement of silica in electronics). However, during this same period it was progressively demonstrated that attaining the full (theoretical) potential of these materials in terms of performance was not easy, namely due to difficulties in producing sufficiently clean (free of impurities such as metal catalyst particles and amorphous carbon) and dimensionally uniform nanotubes and, in the case of polymer nanocomposites, in achieving the required dispersion levels in the matrix. Only a very limited number of products actually attained the commercial stage (mostly automotive and electronic parts, sporting goods, sensors and battery electrodes). More recently, the better understanding of the chemical-physical characteristics and dispersion mechanisms of CNT, together with the advances in manufacturing technologies and in surface functionalization routes, originated a new upsurge in the practical interest in these materials.

These fluctuations in the visibility of CNT and in their real-world applications are typical of a hype cycle of an emerging technology, as illustrated in Fig. 1. Exaggerated expectations were initially created, as the manufacture, characteristics and engineering properties of CNT had not been sufficiently investigated. This created a trough of disillusionment, which affected the interest to conduct (and the capacity to fund) new research. The entrance of graphene derivatives as competitors of CNT for many applications in the early 2000s further complicated the situation. At present, there is renewed optimism concerning the commercial sustainability of CNT. Market studies from 2013 asserting that the global CNT market is expected to grow at an estimated $4 \%$ compound annual growth rate from 2011 to 2016 [53] were revised in 2014 to $15.5 \%$ between 2013 and 2018 [54].

Nonetheless, a significant gap between supply and demand currently still exists. According to De Volder et al. [24], worldwide CNT production increased more than one order of magnitude between 2006 and 2011 (typically, from 200 ton in 2005 to 


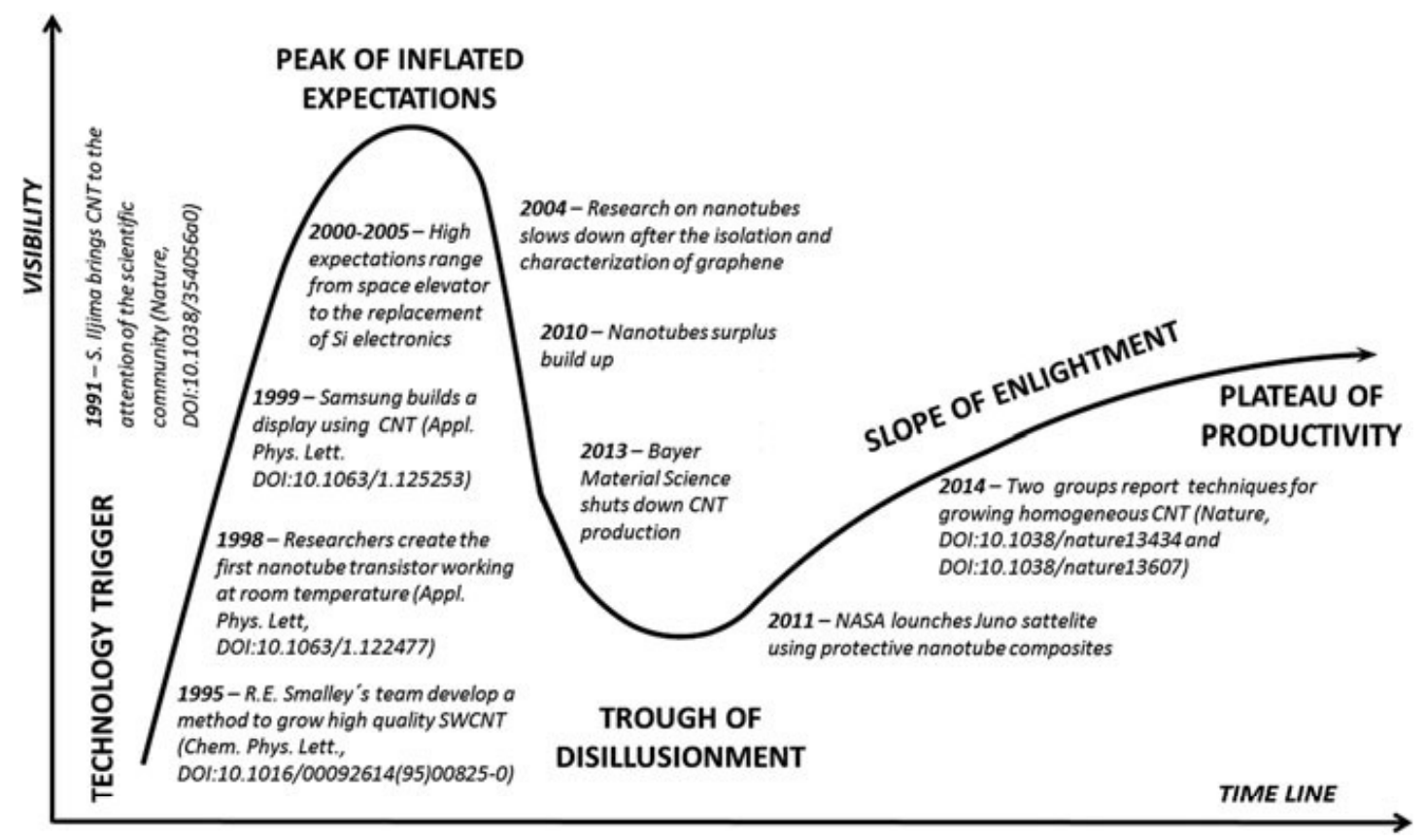

Fig. 1 The hype cycle of carbon nanotubes. Adapted from Davenport [23]

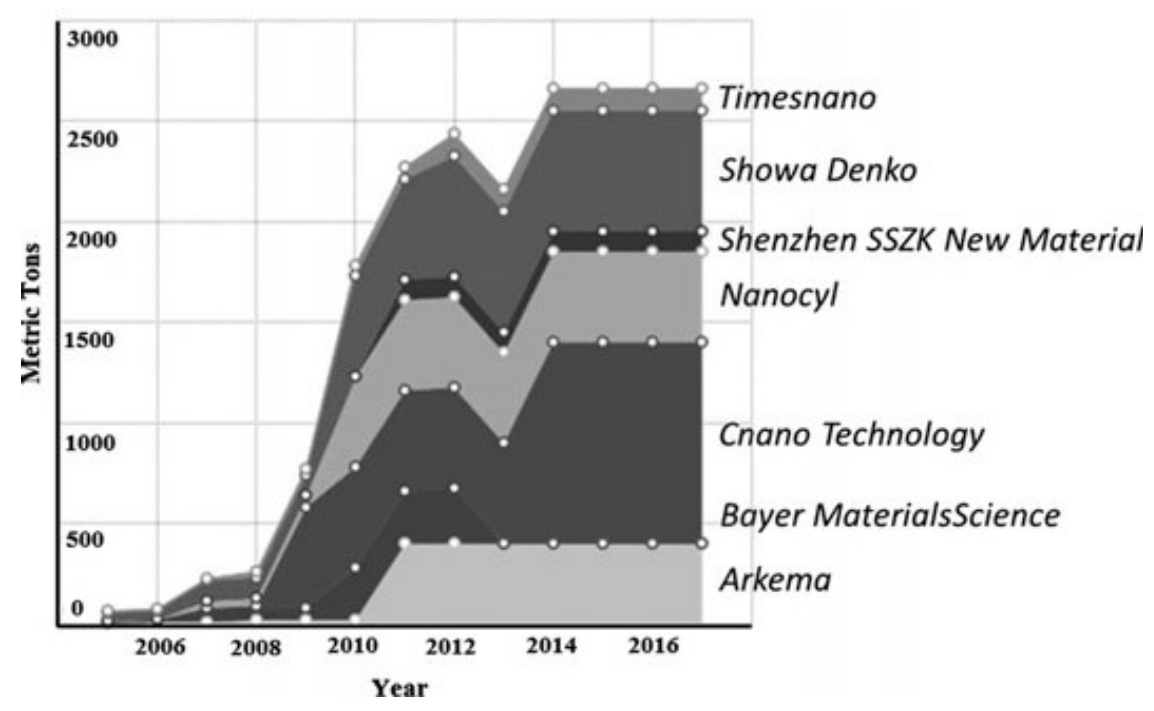

Fig. 2 Main CNT manufacturers (Adapted from: http://cenm.ag/nanotubes2015. Accessed 15 July 2015. Source Lux Research)

approximately 4600 ton in 2011). Figure 2 reveals that CNT manufacture is dominated by a few companies (Showa Denko, CNano Technology, Nanocyl S.A and Arkema), whilst Bayer MaterialScience exited production in 2013, apparently due to excessive market fragmentation (at the time, their capacity was over 200 tons per year). In contrast, there is growing optimism in terms of demand (see Fig. 3), even if data can differ significantly between sources. It is also clear that CNT have been and will continue to be primarily utilized in polymers (at least $60 \%$ of the total 


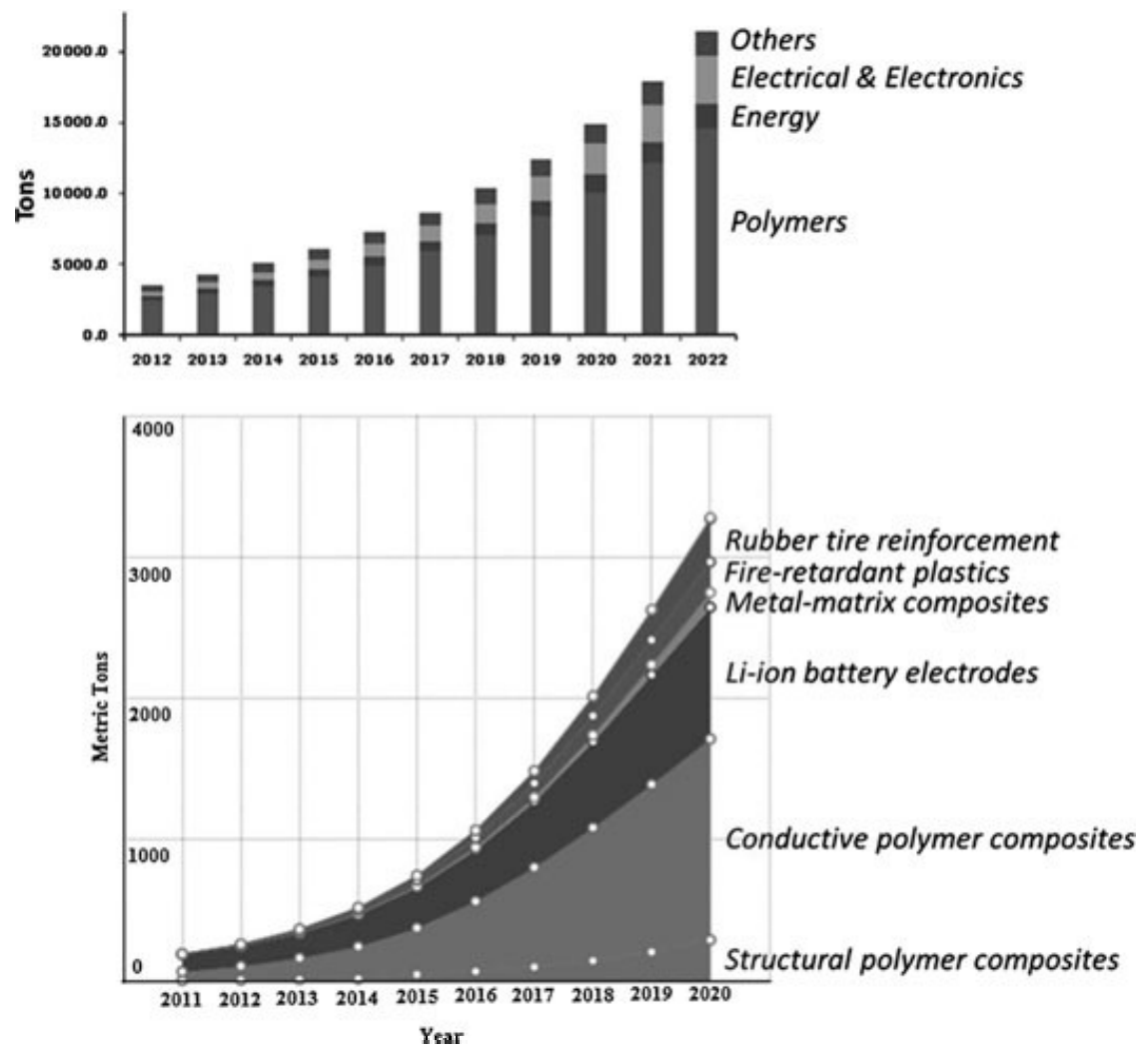

Fig. 3 Market estimates for CNT per area of application. (Top adapted from http://www. grandviewresearch.com/industry-analysis/carbon-nanotubes-cnt-market. Accessed 21 July 2015. Source Grand View Research; bottom adapted from http://cenm.ag/nanotubes2015. Accessed 21 July 2015. Source Lux Research

applications), as consumption of CNT will be certainly facilitated by the observed continuous decrease in prices that result from technological improvements in Chemical Vapor Deposition (CVD) technology. Indeed, prices started at more than $1,000 \mathrm{US} \$ / \mathrm{kg}$ in the nineties, dropping to approximately $100 \mathrm{USD} \$$ in 2011 and probably to less than half of this value by 2016 .

In conclusion, although the commercial viability of CNTs seems guaranteed, the effective growth of practical demand will depend on the efficiency in tackling dominant factors such as price, material quality/purity and consistency, health and safety aspects and, especially in the case of polymer nanocomposites, dispersibility and compatibility with the matrix.

\section{Synthesis and Properties of Carbon Nanotubes and Nanofibers}

The element carbon (C) with atomic number 6 may form hybridized $\mathrm{sp}, \mathrm{sp}^{2}$, or $\mathrm{sp}^{3}$ atomic orbitals, providing such a versatility for chemical bonding that makes it the major element in a variety of materials, from feedstock gases to all organic matter, 
(a)

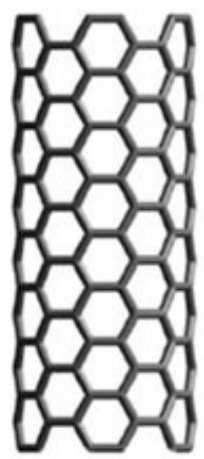

armchair

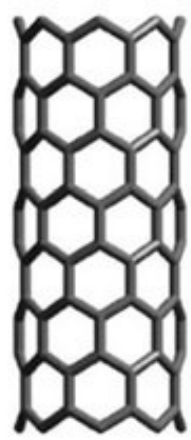

zigzag

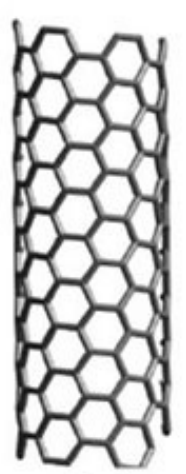

chiral (b)

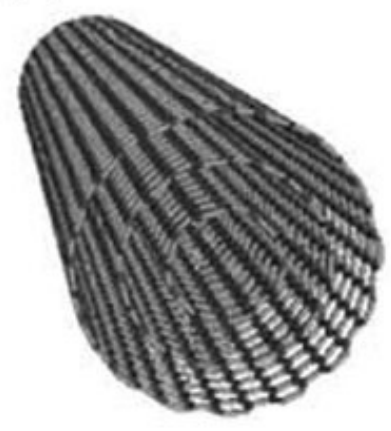

(c)

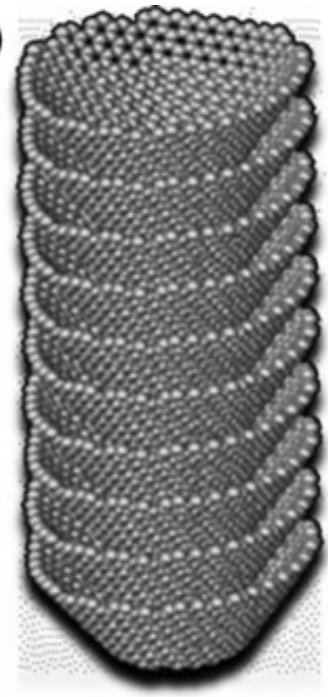

Fig. 4 Representation of the hexagonal graphene layers arrangement to form single wall carbon nanotubes (a), multi wall carbon nanotubes (b) and carbon nanofibers (c)

and to inorganic matter such as diamond and aluminium carbide. $\mathrm{Sp}^{2} \mathrm{C}$ may bond to form a bi-dimensional hexagonal molecular array of $\mathrm{C}$ atoms, designated as graphene. Graphene layers may arrange in different shapes, originating diverse carbon allotropes. For example, graphite results from stacking of graphene layers with an interplanar spacing of $0.335 \mathrm{~nm}$; a single rolled up sheet of graphene forms a cylinder designated as single walled carbon nanotube (SWNT) (Fig. 4a); several concentrically stacked graphene cylinders with an interlayer spacing of $0.344 \mathrm{~nm}$ (as reported by Saito et al. [77] are designated as multi walled carbon nanotubes (MWNT) (Fig. 4b). A diversity of SWNT may be formed depending on the roll-up angle of the graphene sheet relative to the nanotube axis (Fig. 4a), presenting different electronic properties ranging from metallic to semiconducting behaviour [76]. Carbon nanofibers (CNF) are also graphite-based cylindrical hollow fibres, however not only the graphene layers stack in truncated cones, or "stacked cups", as illustrated in Fig. 4c, but they also present larger diameter compared to typical MWNT.

The synthesis of CNT can be achieved through high temperature methods $\left(>1700{ }^{\circ} \mathrm{C}\right)$ such as arc discharge or laser ablation, although presently the larger production rates are achieved at low temperature $\left(<800{ }^{\circ} \mathrm{C}\right)$ by chemical vapour deposition (CVD) methods [21, 72, 89]. Arc discharge methods require high temperature but produce CNT with few structural defects. Laser ablation also provides good quality CNT free from catalyst contamination, but the large number of process parameters involved make it difficult to control the properties of the particles produced. In both cases the CNT are typically contaminated with less structured carbon. Catalytic chemical vapour deposition (CCVD) methods are based on the reaction of an hydrocarbon-rich gas mixture in the presence of a catalyst, activated by heat or other stimuli such as plasma enhancement (PE), microwave plasma or other methods [72]. The process has been extensively studied 
Table 1 Typical properties of CNF, MWNT and SWNT

\begin{tabular}{l|l|l|l}
\hline Property & $\mathrm{CNF}^{\mathrm{a}}$ & MWNT $^{\mathrm{b}}$ & SWNT $^{\mathrm{b}}$ \\
\hline Diameter $(\mathrm{nm})$ & $50-200$ & $5-50$ & $0.6-1.8$ \\
\hline Aspect ratio & $250-2000$ & $100-10000$ & $100-10000$ \\
\hline Surface area $\left(\mathrm{m}^{2} / \mathrm{g}\right)$ & $20-30$ & $50-850^{\mathrm{c}}$ & $\sim 1300^{\mathrm{c}}$ \\
\hline Tensile strength $(\mathrm{GPa})$ & 2.9 & $10-60$ & $50-500$ \\
\hline Tensile modulus $(\mathrm{GPa})$ & 240 & 1000 & 1500 \\
\hline Electrical resistivity $(\Omega \mathrm{cm})$ & $1 \times 10^{-4}$ & $2 \times 10^{-3}$ to $1 \times 10^{-4}$ & $1 \times 10^{-3}$ to $1 \times 10^{-4}$ \\
\hline Thermal conductivity $(\mathrm{W} / \mathrm{m} \mathrm{K})$ & 1950 & $3000-6000$ & $3000-6000$ \\
\hline
\end{tabular}

${ }^{\mathrm{a}}$ Based on Breuer and Sundararaj [13] and Tibbets et al. [91]

${ }^{\mathrm{b}}$ Based on Winey and Vaia [97]

${ }^{\mathrm{c}}$ Theoretical estimate depending on the number of CNT walls, from 40 to 2 walls for MWNT [70]

and the CNT growth parameters are well identified and controlled yielding high purity CNT, however containing residual metal catalyst and a less perfect structure, compared to CNT produced by high temperature methods.

Carbon nanofibers have been known and produced for a long time [7], (Oberlin [64]). Their synthesis is based on catalytic CVD in a process that is similar to CNT production, but their structure and dimensions differ considerably [37, 59, 91]. Although they are formed by $\mathrm{sp}^{2} \mathrm{C}$, their surface chemical activity is higher compared to CNT, while their mechanical and electrical properties are lower. Nevertheless, their lower cost, relatively easier incorporation in matrices and interesting set of mechanical, electrical and thermal properties, make them competitive for a wide range of composite applications. Table 1 presents typical values of physical properties for SWNT, MWNT and CNF, as reported in the literature for nanoparticles produced by different methods.

\section{Carbon Nanotube and Nanofiber Polymer Composites: Properties and Applications}

The unique set of mechanical, electrical and thermal properties of CNT, as well as their large aspect ratio and high surface area, make CNT remarkable fillers for polymer matrices. However, although their excellent properties are expected to translate into high performance composites, other characteristics such as nanoparticle agglomerate formation (arising from CNT or CNF entanglement during growth) may strongly influence composite properties. The as-produced MWNT and $\mathrm{CNF}$ are typically entangled and agglomerated, as represented in Fig. 5a, b, while the SWNT form "ropes", or nanotube strands, strongly attached to each other through Van der Waals interactions. These "ropes" are observed as long fibers with a diameter that may exceed $20 \mathrm{~nm}$ (Fig. 5c). The stable aggregates greatly decrease 

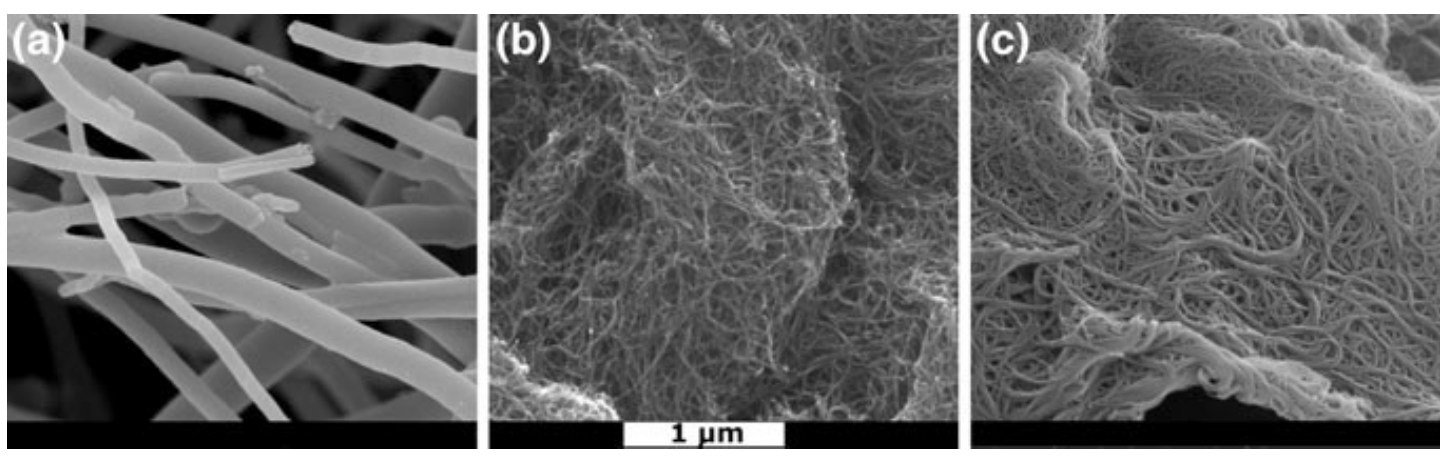

Fig. 5 Scanning electron micrographs of CNF (a), MWNT (b) and SWNT "ropes" (c) observed under the same magnification (same scale bar)

the nanoparticle surface available for interfacial interactions and hinder the dispersion of the individual CNT or CNF in the polymer matrix.

Molecular mechanics and molecular dynamics simulations provide a good insight into the local interactions among individual atoms of CNT and the polymer matrix, helping to understand the load transfer and mechanical behaviour of carbon nanotube/polymer composites. For example, Arash et al. [5] used molecular dynamics simulations to estimate the elastic properties of the interfacial region in CNT/poly (methyl methacrylate) (PMMA) matrix composites under tensile loading. Their simulations estimate that the Young's modulus of a PMMA composite reinforced by an infinite length $(5,5) \mathrm{CNT}$ increases 16 times relative to pure PMMA. They also reported that the CNT/PMMA interfacial strength increases with increasing CNT aspect ratio.

Classical continuum mechanics has been used to study the mechanical response of carbon nanotube/polymer composites with SWNT and MWNT (for example, Wagner [95] and Tu and Ou-Yang [93], respectively), adding to the understanding of interfacial stress-transfer in CNT composites. However, modelling of nanocomposites still provides limited information as it cannot account for all the CNT features, such as structural defects on the nanotube surface, ropes or bundles of nanotubes, and waviness of the nanotubes in the nanocomposites. Thus, real composites present a (quite unpredictable) range of mechanical properties that are dependent on the CNT type and structure, level of entanglement and aggregation. Table 2 provides examples of tensile properties experimentally measured for CNT composites prepared by melt mixing methods, for CNT incorporation levels ranging from 0.1 to $5 \mathrm{wt} \%$. Generally, the addition of CNT has a positive effect on the composite Young's modulus, and this property is sensitive to the wt $\%$ of CNT and to interfacial effects induced by CNT surface functionalization. Composite strength trends are less predictable, since strength is highly affected by interfacial quality, CNT defects, presence of CNT agglomerates, etc. CNT functionalization frequently results in higher composite strength, associated to stronger interfacial strength, as illustrated also in Table 2.

The electrical conductivity of CNT and CNF make them suitable for the preparation of conductive polymer composites. The large aspect ratio of these 
Table 2 Representative results for tensile moduli and strength of CNT/polymer composites produced by melt mixing methods

\begin{tabular}{|c|c|c|c|c|c|}
\hline Matrix/CNT type & $\begin{array}{l}\text { CNT } \\
\text { wt\% }\end{array}$ & $\begin{array}{l}\text { \% increase } \\
\text { Tensile } \\
\text { strength }\end{array}$ & $\begin{array}{l}\% \text { increase } \\
\text { Young's } \\
\text { modulus }\end{array}$ & $\begin{array}{l}\text { CNT \% at } \\
\text { electrical } \\
\text { percolation }\end{array}$ & Reference \\
\hline PP/pristine MWNT & 2 & -0.25 & 15 & 1.1 & \multirow{2}{*}{$\begin{array}{l}\text { Micusik et al. } \\
\text { [55] }\end{array}$} \\
\hline $\begin{array}{l}\text { PP-MA/pristine } \\
\text { MWNT }\end{array}$ & 2 & -88 & 50 & 1.6 & \\
\hline $\begin{array}{l}\text { PP/PP-modified } \\
\text { MWNT }\end{array}$ & 4 & 3 & 42 & 4 & \multirow[t]{2}{*}{$\begin{array}{l}\text { Novais et al. } \\
\text { [62] }\end{array}$} \\
\hline PP/pristine MWNT & 4 & 0 & 6.5 & $<4$ & \\
\hline $\begin{array}{l}\text { PA6/purified } \\
\text { MWNT }\end{array}$ & 1 & -19 & 13 & - & \multirow[t]{2}{*}{ Xia et al. [99] } \\
\hline $\begin{array}{l}\text { PA6/polymer } \\
\text { encapsulated } \\
\text { MWNT }\end{array}$ & 1 & -5 & 34.5 & - & \\
\hline \multirow[t]{2}{*}{$\begin{array}{l}\text { PA6/purified } \\
\text { MWNT }\end{array}$} & 1 & 115 & 71 & - & $\begin{array}{l}\text { Zhang et al. } \\
\text { [101] }\end{array}$ \\
\hline & 2 & 162 & 214 & - & Liu et al. [48] \\
\hline PA6/pristine MWNT & 1 & 164 & 220 & - & $\begin{array}{l}\text { Mahfuz et al. } \\
\text { [51] }\end{array}$ \\
\hline PA6/SWNT & 1.5 & -24 & 15 & - & \multirow{2}{*}{$\begin{array}{l}\text { Bhattacharyya } \\
\text { et al. [11] }\end{array}$} \\
\hline $\begin{array}{l}\text { PA6/SMA-modified } \\
\text { SWNT }\end{array}$ & 1.5 & -17 & -16 & - & \\
\hline PA6/pristine MWNT & 1.5 & 38 & 37 & $<4.5$ & \multirow{2}{*}{$\begin{array}{l}\text { Ferreira et al. } \\
{[27]}\end{array}$} \\
\hline $\begin{array}{l}\text { PA6/Pyrrolidine } \\
\text { functionalized. } \\
\text { MWNT }\end{array}$ & 1.5 & 10 & 10 & $>4.5$ & \\
\hline $\begin{array}{l}\text { HDPE/pristine } \\
\text { MWNT }\end{array}$ & 5 & 12 & 10 & - & $\begin{array}{l}\text { Tang et al. } \\
\text { [87] }\end{array}$ \\
\hline $\begin{array}{l}\mathrm{HDPE} / \mathrm{PEG}-\mathrm{SiO} 2 \\
\text { modified MWNT }\end{array}$ & 1 & 20 & 50 & - & $\begin{array}{l}\text { Zou et al. } \\
{[102]}\end{array}$ \\
\hline LDPE/MWNT & 0.5 & -27 & 6 & - & \multirow{4}{*}{$\begin{array}{l}\text { Yang et al. } \\
\text { [100] }\end{array}$} \\
\hline LDPE/MWNT & 2 & -27 & 20 & - & \\
\hline $\begin{array}{l}\text { LDPE/PE-grafted } \\
\text { MWNT }\end{array}$ & 0.5 & 28 & 61 & - & \\
\hline $\begin{array}{l}\text { LDPE/PE-grafted } \\
\text { MWNT }\end{array}$ & 2 & 23 & 92 & - & \\
\hline $\begin{array}{l}\text { SBBS/purified } \\
\text { MWNT }\end{array}$ & 3 & 23 & 102 & - & Li et al. [45] \\
\hline $\begin{array}{l}\text { EVA/purified } \\
\text { MWNT }\end{array}$ & 3 & -20 & 70 & - & $\begin{array}{l}\text { Peeterbroeck } \\
\text { et al. [68] }\end{array}$ \\
\hline PVA/pristine SWNT & 2.5 & -5 & 35 & - & \multirow{3}{*}{$\begin{array}{l}\text { Paiva et al. } \\
\text { [66] }\end{array}$} \\
\hline $\begin{array}{l}\text { PVA/modified } \\
\text { SWNT }\end{array}$ & 2.5 & 17 & 40 & - & \\
\hline $\begin{array}{l}\text { PVA/modified } \\
\text { SWNT }\end{array}$ & 5 & 54 & 55 & - & \\
\hline
\end{tabular}


Table 2 (continued)

\begin{tabular}{|c|c|c|c|c|c|}
\hline Matrix/CNT type & $\begin{array}{l}\text { CNT } \\
\text { wt } \%\end{array}$ & $\begin{array}{l}\% \text { increase } \\
\text { Tensile } \\
\text { strength }\end{array}$ & $\begin{array}{l}\% \text { increase } \\
\text { Young's } \\
\text { modulus }\end{array}$ & $\begin{array}{l}\text { CNT \% at } \\
\text { electrical } \\
\text { percolation }\end{array}$ & Reference \\
\hline $\begin{array}{l}\text { PLA/pristine } \\
\text { MWNT }\end{array}$ & 0.5 & 8 & 6 & 0.5 & \multirow[t]{2}{*}{$\begin{array}{l}\text { Novais et al. } \\
{[63]}\end{array}$} \\
\hline $\begin{array}{l}\text { PLA/PLA-modified } \\
\text { MWNT }\end{array}$ & 0.5 & 20 & 17 & $1.5-2.0$ & \\
\hline \multirow[t]{2}{*}{ PET/pristine SWNT } & 0.1 & 8 & 20 & \multirow[t]{2}{*}{1} & \multirow{2}{*}{$\begin{array}{l}\text { Anand et al. } \\
{[4]}\end{array}$} \\
\hline & 1 & 24 & 58 & & \\
\hline
\end{tabular}

Whenever available, the wt $\%$ of CNT required to reach electrical percolation is included

nanoparticles allows the modification of the electrical properties of their composites even at low filler content. The electrical percolation threshold varies with the CNT or CNF type, but also with the polymer nature, dispersion level, dispersion method, etc. Bauhofer and Kovacs [9] analyzed a large amount of published data concerning electrical conductivity of polymer/CNT composites produced by solution and melt mixing methods. They concluded that the minimum percolation threshold and maximum conductivity are mainly dependent on the type of polymer matrix and dispersion method and emphasized that non-entangled MWNT originated higher composite conductivity (50 times higher) compared to highly entangled MWNT. Figure 6 [9] presents the values of maximum conductivity as a function of CNT concentration for composites with different types of CNT and polymers.

Fig. 6 Maximum conductivity reported for composites produced with different matrices and CNT types, at respective CNT concentration (experimental results selected from data published between 19982007. Adapted from Bauhofer and Kovacs [9])

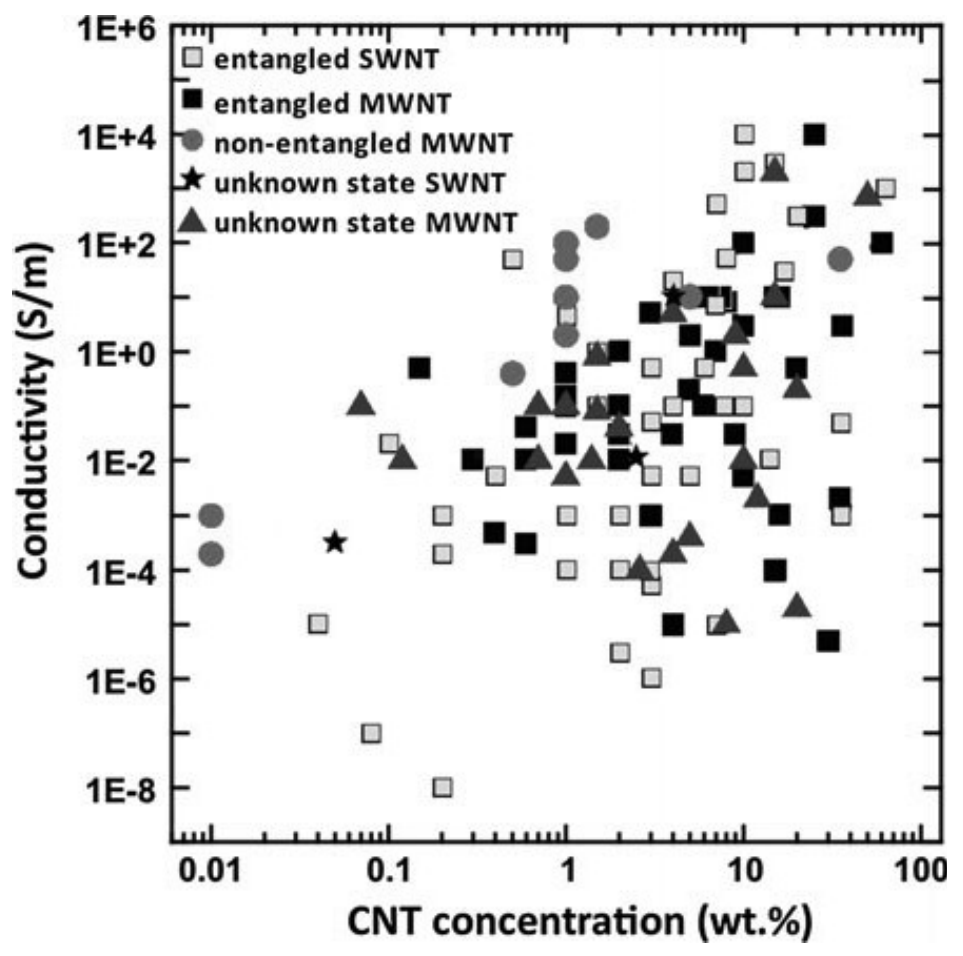


The electrical conductivity of $\mathrm{CNF} /$ polymer composites was also observed to be significantly affected by the polymer type and physical properties (surface tension, crystallinity, polarity and molecular weight), as reported by Al-Saleh et al. [2]. The authors underlined the influence of the processing method on the CNF electrical percolation concentration, as well as the importance of selecting dispersion conditions that do not reduce the $\mathrm{CNF}$ aspect ratio. Percolation threshold for $\mathrm{CNF} /$ polymer composites reported in the literature range from 2 to $18 \mathrm{wt} \%$, varying with CNF, polymer type and mixing method.

$\mathrm{CNT}$ and CNF are also expected to increase the thermal conductivity of their polymer composites, although only minor increments were reported so far. Thermal properties are largely dependent on the CNT length and alignment. High thermal conductivity values were measured for aligned CNT fibers produced from forests, such as reported by Myhew and Prakash [58]. The authors measured the thermal conductivity of fibres produced with CNT to be $448 \pm 61 \mathrm{~W} /(\mathrm{m} \mathrm{K})$ and for $\mathrm{CNT} /$ polymer composite fibres to be $225 \pm 15 \mathrm{~W} /(\mathrm{m} \mathrm{K})$.

Polymer nanocomposites with good mechanical and electrical properties already find a number of applications. They are used to manufacture fuel lines and filters that dissipate electrostatic charge and parts for electrostatic-assisted painting for the automotive industry, electromagnetic interference (EMI) — shielding packages and wafer carriers [24], touch panels and displays, diodes and transistors for the microelectronics and electronics market, electrical wire and cable and sporting goods (such as racquets, golf clubs, surfboards and ice hockey sticks). In the form of arrays, films, filaments or yarns, CNTs have also been utilized in battery/capacitor electrodes, membranes, sensors, heat exchangers, wind turbine blades and in biomedical applications (drug delivery, biosensors).

The continuous drop in price of CNT will certainly contribute to their rising application, especially in the composites market (see Fig. 3). In 2011, the Inno.CNT venture was established in Germany as an alliance between academia and industry, supported by the federal government, to foster a breakthrough in CNT technology and applications [34]. Figure 7 illustrates the selected fields and offers a few examples of the applications under development by this initiative, thus constituting a good representation of the emergent CNT market. Another stimulating field is

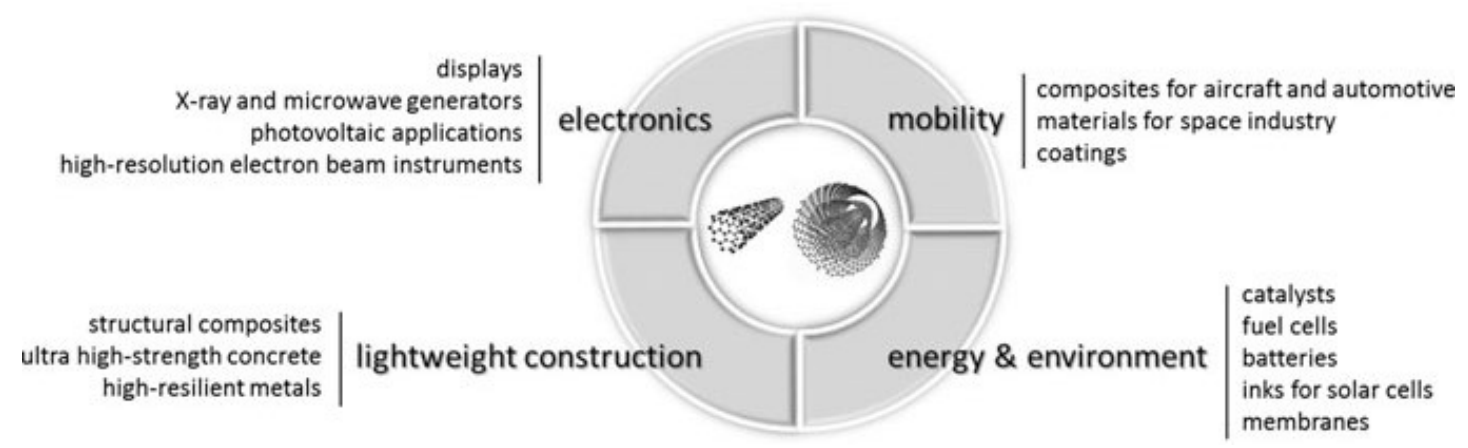

Fig. 7 Examples of applications making use of CNTs in the fields focused by the German Inno. CNT initiative (Inno.CNT 2011) 
smart textiles, where CNT can be used to manufacture different types of sensors, such as for movement (torsion, displacement) and health and safety (temperature, liquid and gas exposure), or wearable electronics. Conductive adhesives, as well as biomedical detection, imaging and therapeutics are also potential areas of product development.

\section{Preparation of Nanocomposites}

\subsection{General Preparation Methods}

In order to obtain polymer/CNT or polymer/CNF nanocomposites with optimal performance, it is generally necessary to ensure extensive dispersion of the filler in the polymer matrix (but the required dispersion levels to attain the best mechanical properties or electrical conductivity may be different). Dispersion involves the disruption of the initial agglomerates (the process is sometimes denoted as deagglomeration) until the dominant size of the filler becomes nanoscopic (ideally, until disintegration into isolated particles/fibers is achieved). This process must be accompanied by adequate distributive mixing, in order to assure spatial compositional homogeneity. The improvement of the interaction between filler and polymer can be approached by adding surfactants, or by functionalizing the surface of the as-produced fillers $[12,18,49]$. In practice, the dispersion of CNT and CNF is quite difficult $[3,36,40,83]$ due to three main causes:

- They grow as highly entangled agglomerates of several microns or even millimeters in size;

- Van der Waals interactions between individual tubes or fibers promote significant aggregation; together with the physical entanglement, the outcome are highly cohesive agglomerates;

- Chemical inertia of the nanoparticle surface creates weak interfaces with most polymers (the process can be further aggravated by surface contamination resulting from the manufacturing technique), which may prevent reaching the hydrodynamic stresses required for dispersion, as well as the load transfer necessary for enhanced mechanical response under service conditions.

Several methodologies have been developed for the manufacture of polymer/CNT and polymer/CNF composites [13, 79]. In situ polymerization of the monomer in the presence of the filler (e.g. Lin et al. [46], Wu and Chen [98]), solution processing (e.g. Qian et al. [74], Safadi et al. [75], Chen et al. [16], Huang and Terentjev [31], Thomassin et al. [90]) and melt mixing (e.g. Socher et al. [85], Novais et al. [61, 62], Sathyanarayana et al. [80], Jamali et al. [35], Novais et al. [63]) are the most utilized, but other routes have also been explored [79].

In situ polymerization of the monomer in the presence of an initiator and CNT or $\mathrm{CNF}$ allows the production of composites with high filler loadings. The technique is 
particularly suitable for insoluble and thermally unstable polymers. Depending on the target molecular weight (MW) and MW distribution, chain transfer, radical, anionic and ring-opening polymerization routes can be pursued. Covalent grafting of polymers to the nanotubes can be made either as "grafting from" (i.e., initial immobilization of the initiators onto the filler surface followed by the attachment of the monomers and subsequent growth into polymers) or as "grafting to" (when previously end-functionalized polymer macromolecules are attached to functional groups on the filler), leading to distinct grafting densities. Concurrently, the low viscosity levels of the starting monomer enable its efficient infiltration into the filler bundles, thus contributing to an easier deagglomeration of the latter.

Solution processing is widely used due to its simplicity: filler, surfactant and polymer are mixed in a suitable solvent, followed by evaporation of the latter with or without vacuum to (frequently) form a film. Agitation of the low viscosity medium (ultrasonication is often employed) facilitates infiltration and deagglomeration. The former is easier if the CNT/CNF are first dispersed in the solvent, whereas the increased viscosity of a polymer solution will be more efficient for deagglomeration. Although solution processing is not easily scalable and total removal of the solvent may be problematic, it is often adopted for thermoset matrices (e.g. epoxy), which do not require significant shear magnitudes [79]. Conversely, it is unsuitable for insoluble polymers.

\subsection{Carbon Nanotube and Nanofiber Functionalization for Interfacial Enhancement}

The smooth CNT surface (at the atomic level) is prone for physical adsorption of specific molecules and may be chemically modified, or functionalized, by non-covalent chemistry [25]. In this process, the CNT physically adsorb molecules that are constituted by a CNT-compatible part, such as an aromatic moiety and a solvent-compatible part. This type of functionalization is most efficient in the preparation of stable CNT suspensions in solvents, including water $[6,25]$ and find applications in solution-based composites.

Strong physical interactions help enhancing CNT/matrix interface; however, covalent bonding leads to the formation of much stronger interfaces and thus to higher stress transfer efficiency. It is generally recognized that adequate covalent functionalization of the CNT or CNF surface leads to improved mechanical properties of their polymer composites. A considerable number of organic reactions may be used to functionalize the $\mathrm{sp}^{2}-\mathrm{C}$ of CNT surfaces, as described by Hirsch [30] and Tasis et al. [88], for example. The more common approach is based on CNT or CNF oxidation using oxidizing inorganic acids, mixture of acids and other oxidative reagents [22]. These methods are often used as cleaning procedure to remove disordered carbon and purify pristine CNT. Depending on the reaction conditions, oxidative methods bond oxygen-containing groups to the CNT surface, 


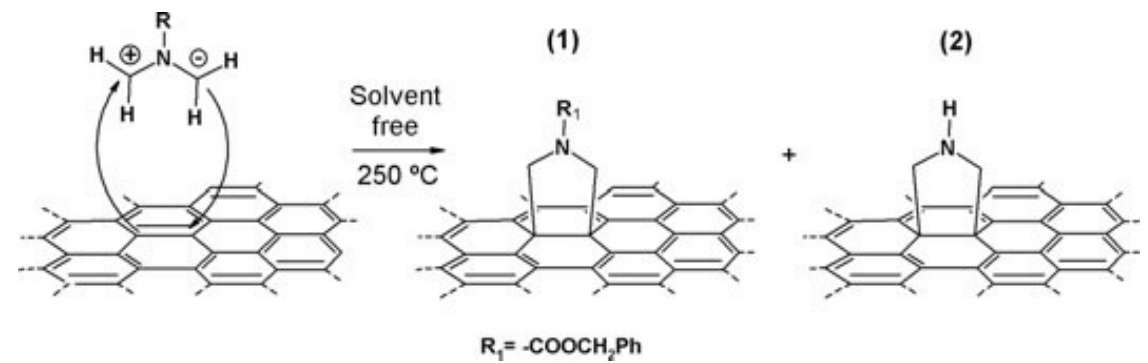

Fig. 8 Functionalization scheme for the 1,3-dipolar cycloaddition of azomethine yilides and products formed under solvent-free reaction conditions. Adapted from Paiva et al. [63]

which may further react through tailored reaction routes. However, extensive oxidation also induce CNT breakage and a considerable decrease of the CNT aspect ratio, which is detrimental for composite properties.

An interesting class of covalent functionalization routes is based on addition reactions to the CNT or CNF surface $\pi$-electrons. Cycloaddition reactions were successfully applied to these materials, such as carbene [2+1] cycloaddition [17], nitrene functionalization [30], and Diels-Alder cycloaddition [38, 73]. The 1,3-dipolar cycloaddition of azomethine ylides, first used for the functionalization of CNT by Georgakilas et al. [28], originates pyrrolidine functionalized CNT (or CNT with substituted pyrrolidines), as represented in Fig. 8 (2 and 1, respectively). This reaction was carried out in the solid state [65], reducing the reaction time from several days to $3 \mathrm{~h}$ and eliminating the use of dangerous solvents.

The CNT or CNF/polymer interactions may be maximized if the nanoparticle surface is modified by covalently bonding polymer molecules. Covalent functionalization of CNT with polymers was achieved by in situ polymerization [19, 44]. A simple route for the covalent bonding of polymer molecules to CNT was achieved under melt processing conditions, thus avoiding in situ polymerization procedures. This method uses solid-state pyrrolidine-functionalized CNT [65], as they were observed to bond to specific polymers under melt processing conditions. The functionalized CNT are thermally stable up to approximately $300{ }^{\circ} \mathrm{C}$, allowing for melt mixing with several polymers without thermal degradation of the functional groups. At these high temperatures and in the polymer melt the pyrrolidine groups were observed to be highly reactive towards ester-based polymers, as well as polycarbonates and maleic anhydride modified polymers. Reaction in solution was only observed with maleic anhydride-modified polymers. This enabled reactive extrusion, forming composites with polymer functionalized CNT during the melt mixing step $[62,63]$.

\subsection{Melt Mixing Methods}

Melt mixing (also known as compounding) is probably the most common route to prepare thermoplastic polymer/CNT or polymer/CNF nanocomposites. It consists 
in the physical/mechanical mixing of the filler with amorphous polymers above their glass transition temperature, or with semicrystalline polymers above their melting temperature. The application of intensive hydrodynamic stresses (usually of the shear type, but occasionally also extensional stresses) resulting from the laminar flow of a highly viscous system causes progressive deagglomeration and disintegration of the filler bundles, with simultaneous distribution in the polymer melt. The method is simple, adaptable to the specific characteristics of different polymer/carbon-based filler systems (tunable process parameters include type and geometry of the equipment and operating conditions) and attractive within an industrial context, as it uses commercial machines (often twin screw extruders, that are capable of a continuous high yield) and can be scaled-up directly. It is also viable for those polymers that cannot be utilized in solution processing. A recent practical trend consists in the preparation (by material manufacturers) of well dispersed masterbatches where the filler is present at high concentration, that are subsequently diluted by processors or end users to the required filler content by mixing with more polymer. This approach brings two major benefits: (i) processors or end users are no longer exposed to direct contact with nanoparticles, which brings about significant health and safety gains, as well as logistical simplifications; (ii) the masterbtach can be directly used in standard shaping techniques, such as extrusion and injection molding. A proposed variant consists in preparing polyethylene/CNT concentrates (with CNT loadings typically in the range 24-44 wt $\%$ ) followed by dilution with other polymers (for instance, polycarbonate, polyamide). As a consequence of the high interfacial energy between CNT and polyethylene, the filler migrates into matrix polymers with lower interfacial energy [71].

Due to its practical importance, melt mixing of CNT or CNF with thermoplastic matrices will be analyzed below in greater detail. The effect of material and process parameters will be discussed and illustrated with a few examples. A general dispersion mechanism will be presented.

Thermoplastic polymer nanocomposites are usually prepared in batch mixers or extruders. The former are useful for laboratorial $\mathrm{R} \& \mathrm{D}$ and include internal intensive mixers consisting of two counter-rotating rotors (also known as Haake or Brabender mixers, two well-known equipment manufacturer brands), micro-compounders and small-scale prototype devices (for example, Maric and Macosko [52], Lin et al. [47], Novais et al. [61]). At the industrial production scale, intermeshing conjugated co-rotating twin screw extruders are the most popular machines. These are also widely utilized for other plastics compounding operations, such as additivation and polymer modification and blending, especially due to two dominant features: (i) modular construction, i.e., the geometry of both screw and barrel can be changed, enabling to define and adjust the sequence and configuration of process steps such as melting, mixing, devolatilization, secondary feeding, pressure generation, etc. (ii) the operator has independent control over output, screw speed and temperature, i.e., over residence time and shear intensity. Thus, the machine can be adapted both in terms of geometry and operating conditions to the needs of a particular system. The screws usually consist of a series of adjacent individual elements that are hold together at the tips. A typical screw profile includes 
conveying elements separated by mixing elements that are restrictive in terms of forward transportation and, depending on their geometry, induce more or less intensive distributive or distributive/dispersive mixing. In conveying sections, the material follows a figure-of eight pattern along the helical channels of the partially filled screws, producing some degree of distributive mixing. Once the material attains a restrictive element (typically, a kneading block comprising disks staggered at a negative or neutral angle, or a conveying element with a negative helix angle), it accumulates immediately upstream, in order to generate the pressure required to continue the flow in the axial direction. The higher the pressure required, the longer the length of the conveying section that works fully filled. Restrictive elements create a complex 3D flow and can induce significant shear and extensional stresses, according to their arrangement (see also Kohlgruber [41]). Generally, when preparing polymer nanocomposites, the first restrictive section upstream prompts polymer melting due to the combined contribution of local frictional forces, pressure and heat transfer. The filler is then added and the material flows through various mixing zones downstream, which are generally designed to induce dispersion and distribution without causing excessive filler damage (e.g. fiber breakage) and/or viscous dissipation, which could cause thermal degradation of the matrix and/or surfactant. Prior to generating pressure for extrusion through the die, the material may flow through a devolatilization zone.

It is also important to note that nanocomposites are typically subjected to two thermomechanical sequences, compounding and shaping. During the first, specialty equipment such as the twin screw extruders presented above are capable of generating during sufficient time the stress levels and flow patterns assuring adequate filler dispersion and distribution in the matrix. Subsequent extrusion or injection molding (the two most industrially relevant polymer processing techniques) will generate much lower stress levels, simpler flows and, particularly in the case of extrusion, may subject the composite to significant stretching/orientation. This means that: (i) probably, the necessary dispersion levels should be achieved during compounding, as processing will bring about a small additional contribution; (ii) the viscoelastic properties and the thermal stability of the as-compounded nanocomposite are essential for trouble-free shaping; (iii) specific processing steps, such as axial stretching, may cause an increase in the distance between neighboring individual filler particles, thus affecting, for example, the electrical performance (i.e., creating the need either to achieve higher dispersion levels, or to use higher filler concentrations than initially anticipated).

CNT or CNF dispersion in a molten matrix is a complex process that is influenced by a number of material and processing factors, at various length scales (see Fig. 9). Material parameters encompass agglomerate size, structure and cohesion, surface energy and purity of the filler, as well as viscosity levels, affinity with the filler and thermal stability of the polymer matrix [40]. Processing factors mainly involve velocity fields, intensity and type of the exerted hydrodynamic stresses (i.e., shear versus extensional) and residence time [35, 39, 47]. Indeed, it has been shown both for immiscible fluid systems and solid suspensions (including polymer-clay 

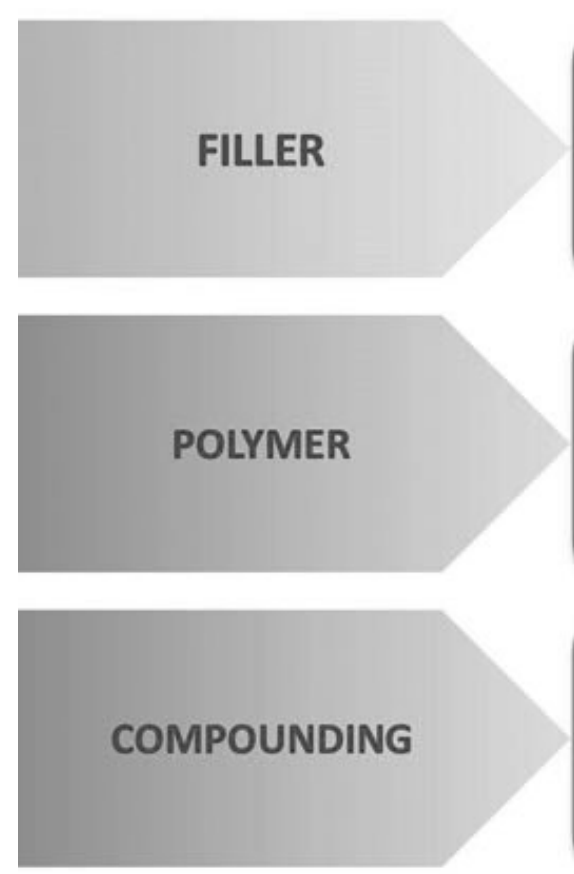

Type

Dimensions

Cohesion (of agglomerates)

Purity

Affinity with polymer

\section{Viscosity}

Thermal stability

Affinity with filler

(Twin screw extrusion)

Screw profile

Feed rate

Feed sequence

Screw speed

Fig. 9 Main parameters affecting the dispersion of carbon-based fillers in thermoplastic polymer matrices by melt mixing

nanocomposites) that extensional flow promotes dispersion more efficiently than pure shear flow [29, 92].

Since the various manufacturers produce carbon-based fillers with distinct characteristics, it is not surprising that, under identical compounding conditions, nanocomposites with different morphologies will be obtained. This is exemplified in Fig. 10 for the electric conductivity of various Polyamide12/CNT nanocomposites, each containing a different commercial CNT (the figure also includes, for comparison purposes, a carbon black (CB) alternative). The electrical percolation threshold is attained for separate incorporation levels of the various CNT (with carbon black requiring much higher concentrations) [84]. Pötschke and co-workers $[42,43,69,84]$ found a correlation between dispersibility of CNT and bulk density of the initial agglomerates). Likewise, Salzano de Luna et al. [76] showed that synthesized CNT particles in the form of small and loosely packed clusters made by interwoven bundles of combed yarns of nanotubes were easier to disperse then the reference denser commercial counterparts. Matrix viscosity is also a primary parameter. Socher et al. [85] revealed that dispersion of CNT agglomerates increased with increasing matrix viscosity, due to the higher input of mixing energy. In addition, different degrees of nanotube shortening during mixing were found when using matrices with varying viscosities. However, the lowest electrical percolation thresholds were always found in the composites based on the lower viscosity matrix.

It has been extensively demonstrated that polymer/CNT and polymer/CNF nanocomposites prepared by melt mixing typically contain aggregates (this 
(a)

(b)

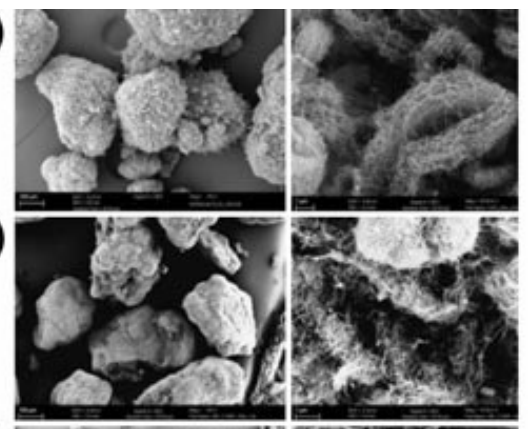

(c)
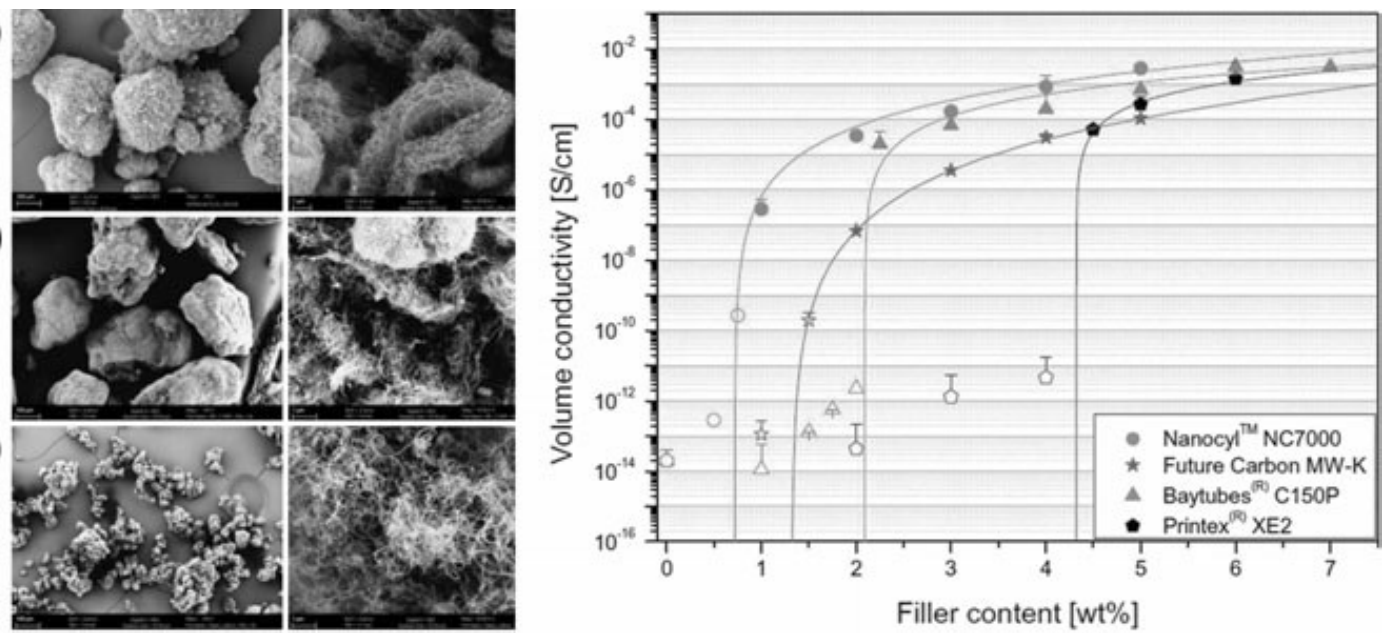

Fig. 10 Commercial CNT powders and electrical volume conductivity of the corresponding composites with Polyamide 12. Left CNT as seen by scanning electron microscopy at two magnifications: a Nanocyl ${ }^{\mathrm{TM}}$ NC7000, b Baytubes C150P, c FutureCarbon CNT-MW-K. Right Effect of filler content on the electrical volume conductivity of PA12/MWNT and PA12/carbon black (Printex XE2 from Evonik Degussa GmbH, Germany). Adapted from Socher et al. [84]

designation is used here for clusters of particles that are smaller than the initial agglomerates), together with well dispersed particles, and that the size and number of the former strongly depend on the melt mixing method and procedure [10, 32, 67]. For instance, Fig. 11 depicts representative optical microscopy and SEM micrographs of polypropylene/CNF nanocomposites (containing either as-received or functionalized CNF (FCNF)) prepared by twin screw extrusion and by a prototype mixer generating a strong extensional flow component [62]. The difference in the levels of dispersion of the various systems is evident, smaller particles being present in the samples containing CNF and produced by the prototype mixer and in the composite

(a)

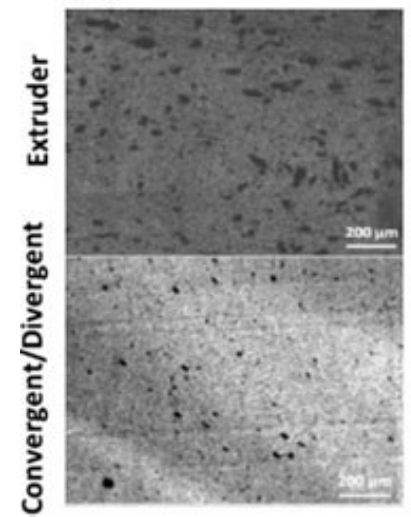

(b)

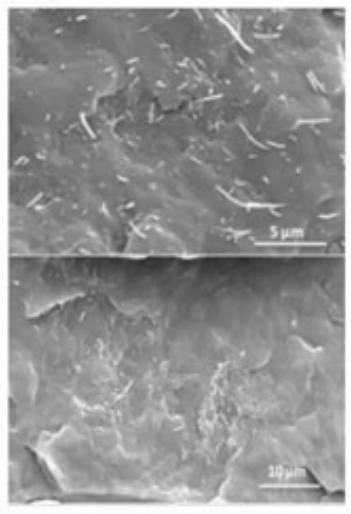

(c)

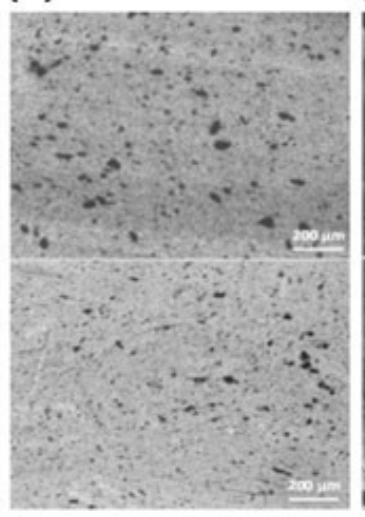

(d)

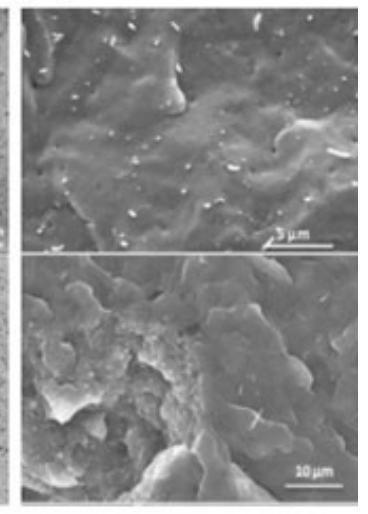

Fig. 11 Optical (a and c) and scanning electron microscopy (b and d) micrographs of polypropylene/CNF composites manufactured by twin screw extrusion and by a prototype extensional mixer. The first two columns correspond to composites containing CNF, the remaining refer to composites with functionalized CNF. Adapted from Novais et al. [61] 
with FCNF prepared by the extruder. This outcome probably results from the differences in the melt viscosity of the two types of composites (caused by the corresponding distinct filler/matrix adhesion), together with the distinctive flow characteristics created by the two types of equipment. Even in the case of the dilution of a masterbatch, adequate matrix viscosity and filler/matrix chemical compatibility must be ensured in order to prevent the survival of large aggregates [55].

When using twin screw extruders, separate feeding of polymer and filler (the latter is added after the former is molten) usually yields better composite homogeneity than joint feeding at the main hopper. Using a Polyamide/CB system, Carneiro et al. [14] showed experimentally that in joint feeding de-mixing of the polymer + filler premix develops during solids conveying and that at the start of the first kneading zone the two materials are segregated to a point where during flow along this zone there is only limited opportunity for the efficient intermingling of the two components. Conversely, in the case of separate feeding, Carbon black falls directly onto a stream of molten polymer, so that distributive mixing immediately develops and, upon reaching the upcoming kneading zone, dispersion and distribution can be very efficient. Nevertheless, Muller et al. [60] observed that filler type may influence the choice of the best feeding mode. Thus, in order to obtain better dispersion of CNT in polypropylene or in polycarbonate, as well as lower electrical resistivity and good mechanical properties, it was found that separate feeding should be selected for CNT Nanocyl ${ }^{\mathrm{TM}}$, which exhibits a loosely packed structure and a lower agglomerate strength, whereas the denser structure of CNT Baytubes ${ }^{\mathrm{TM}}$ advised the adoption of joint feeding (Fig. 10 portrays the morphology of these two commercial products). In turn, setting an optimum extruder screw profile may not only guarantee the appropriate and efficient sequence of the necessary process steps for compounding (typically, as seen above, polymer feeding and melting, feeding of the filler, mixing, devolatilization and pressure generation), but also the adequate dispersion and distribution of the filler in the matrix. For this purpose, the number, length and geometry of the restrictive screw elements (particularly the staggering angle and the length of the individual disks) must be carefully chosen, in order to create the appropriate type and level of stresses and residence time, as well as a suitable flow kinematics. Neutral and negative staggering angles, as well as thicker disks, will create both dispersive and distributive mixing, whilst positive angles and thin disks will induce distributive mixing. However, a too restrictive screw can suffer from limited throughput capacity, considerable energy consumption and insufficient devolatilization, all due to the high average degree of screw filling, and can also cause material degradation owing to viscous dissipation. Conversely, a too mild profile will face difficulties in melting the polymer and in creating the stress levels and residence time required for dispersion.

The effect of the operating conditions on dispersion has been extensively investigated [3, 32, 39, 61, 67, 94]. Improvement of dispersion with increasing screw speed is often reported and attributed to the accompanying higher stress levels. However, the viscous dissipation associated to screw speed may induce degradation and deterioration of the composite performance (it seems worth reminding that viscous dissipation is proportional to viscosity and to the square of 
the shear rate). Also, high screw speeds diminish the degree of screw fill and the residence time (when the remaining parameters are kept constant). High throughputs entail a reduction of the residence time and an increase of the degree of screw fill, both hindering dispersion. Barrel set temperatures essentially influence the viscosity of the system. In principle, lower melt viscosities facilitate infiltration into the CNT agglomerates, whereas higher viscosities should bring about the higher hydrodynamic stresses required for deagglomeration. The Specific Mechanical Energy consumption (SME) is a global process parameter that is often used to characterize the intensity of the thermo-mechanical environment created inside a twin screw extruder during a particular operation. It is defined as the amount of power input by the motor into each kilogram of material being processed. Multiple attempts to correlate dispersion of nanocomposites with SME have been made, but they obtained limited success. This is probably due to the contribution of factors that are not taken in by this parameter, such as the axial residence time, degree of fill and melt temperature profiles. In conclusion, for each nanocomposite, an optimum combination of screw design and operating conditions will probably exist, albeit being difficult to forecast without performing some preliminary testing.

Even if there is obvious useful value in correlating material and process parameters with final dispersion levels (in turn, correlations between the latter and the final properties are also essential), studying the spatial or temporal evolution of the process should provide important insights into the dispersion mechanisms of carbon-based fillers and thus assist practical process setup and optimization. Surprisingly, this type of studies is relatively scarce [3, 35, 61, 62]. Figure 12 shows the development of the dispersion of polypropylene/CNT composites along a prototype extensional mixer (same equipment as the one mentioned above and used to produce the material depicted in Fig. 11) and along a co-rotating twin screw extruder (Fig. 12a, b, respectively) [35, 62]. In the first case, the graphs illustrate the progress of the average agglomerate area and of the electrical resistivity of the composite through a series of flow channels (labelled as pairs of rings) that create a sequence of repetitive convergent/divergent flows, when processing at 100 and $3000 \mathrm{~s}^{-1}$. The far from linear evolution of dispersion is obvious. Since the area of the smallest agglomerates of the as-received in powder form CNT is approximately $3.58 \times 10^{5} \mu \mathrm{m}^{2}$, and the initial average value of approximately $1000 \mu \mathrm{m}^{2}$ is measured at the first pair of rings when processing at $100 \mathrm{~s}^{-1}$, a significant dispersion took place upon flow through the first convergence. Thus, even at this relatively low shear rate, the hydrodynamic stresses generated overcome the cohesive strength of the agglomerates. After this initial step, dispersion seems to proceed gradually, but after a certain residence time (corresponding to attaining pair 4) faster dispersion is again triggered. This behavior is matched by an equivalent decline of the electrical resistivity between pairs numbers 7 and 8 . Once smaller aggregates were formed, further progress in dispersion seems to require higher hydrodynamic stresses and/or longer residence times, as inferred from the little evolution in dispersion beyond pair 6 (and in electrical resistivity after pair 8). Processing at a high wall shear rate $\left(3000 \mathrm{~s}^{-1}\right)$ reduces the size of the particle clusters present after the first pair of rings down to roughly half the size of those 

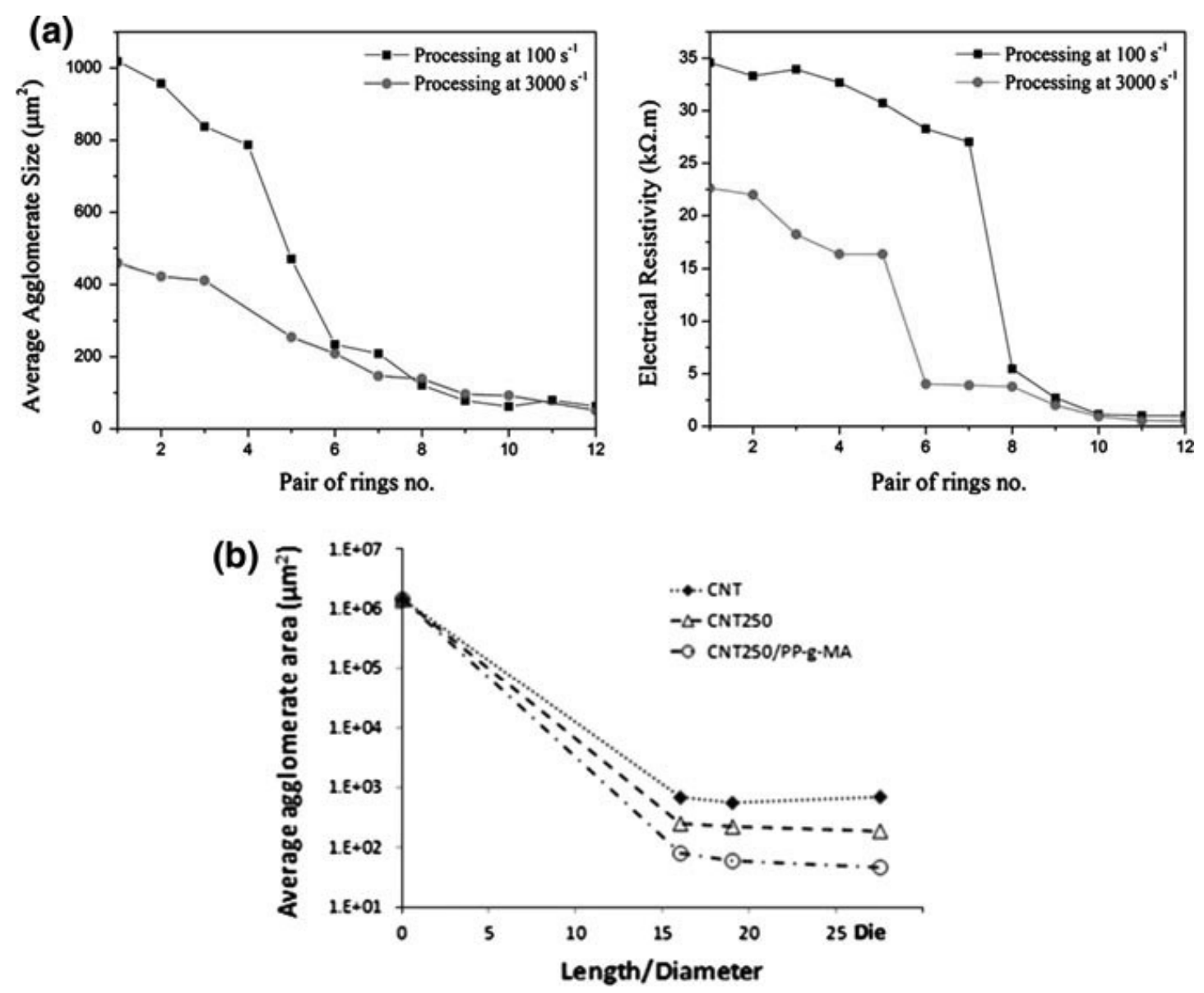

Fig. 12 Evolution of the dispersion of polypropylene/CNT composites along the length of the mixing device; a average agglomerate area (left) and electrical resistivity (right) along a prototype extensional mixer, at two shear rates (adapted from Jamali et al. [35]); b average agglomerate area along a twin screw extruder, using three types of CNT: as-received (CNT), functionalized by the 1,3-dipolar cycloaddition reaction of azomethine ylides at $250{ }^{\circ} \mathrm{C}$ (CNT250) and CNT250 further functionalized with PP-g-MA and with PP molecules bonded to the CNT surface (CNT250/PP-g-MA) Adapted from Novais et al. [62]

seen at $100 \mathrm{~s}^{-1}$. This is followed by a gradual dispersion until reaching dispersion levels similar to those obtained at $100 \mathrm{~s}^{-1}$. Still, the electrical resistivity also shows a sharp decline, now between pair of rings 5 and 6, i.e., earlier than in the preceding condition. Since data on level of dispersion and electrical conductivity were made available, the existence of a correlation between both could be investigated. Indeed, an electrically conductive network seemed to be formed when at least $50 \%$ of the surviving aggregates had an area smaller than $2000 \mu \mathrm{m}^{2}$ [35]. When using an extruder (Fig. 12b), Novais et al. [62] observed that most of the decrease in agglomerate size took place along the first half of the extruder, up to the first kneading zone. Here, the screw channels work fully filled due to the flow restriction created and temperatures are still low, as polymer melting is ongoing. Hence, substantial hydrodynamic stresses may develop, together with a relatively large local residence time and a complex 3D flow. A comparable behavior has been reported for other types of nanocomposites and polymer blends [8, 50]. Although 
higher stresses and/or longer mixing times are probably needed to break-up the aggregates formed upstream, temperature is much higher in the second part of the extruder and thus the process is difficult. Anyway, dispersion should depend on the cohesive strength and interfacial bonding of each system, differences being perceived in Fig. 12b for the three types of CNT that were used in the experiments: (i) as-received (CNT), (ii) chemically functionalized CNT by the 1,3-dipolar cycloaddition reaction of azomethine ylides (discussed earlier in this chapter) performed at $250{ }^{\circ} \mathrm{C}(\mathrm{CNT} 250)$ and (iii) $\mathrm{CNT} 250$ further functionalized with PP-g-MA and with PP molecules bonded to the CNT surface by reaction of the NH-pyrrolidine groups with the anhydride grafted on the PP-g-MA (CNT250/PP-g-MA) (the aim was to create covalent bonding between the pyrrolidine groups at the CNT surface with the maleic anhydride on the PP-g-MA molecules).

The evolution of the dispersion of a polypropylene/CNF composite along the length of the extensional mixer, as depicted in Fig. 13 [61], can be distinct from that pictured in Fig. 12a for a PP/CNT system. Data for composites incorporating as-received $\mathrm{CNF}$ and functionalized $\mathrm{CNF}$ (using the 1,3-dipolar cycloaddition reaction cited above) are presented in terms of Area Ratio $\left(A_{R}\right)$, that is, the ratio of the sum of the areas of all surviving clusters to the total area of composite analyzed.

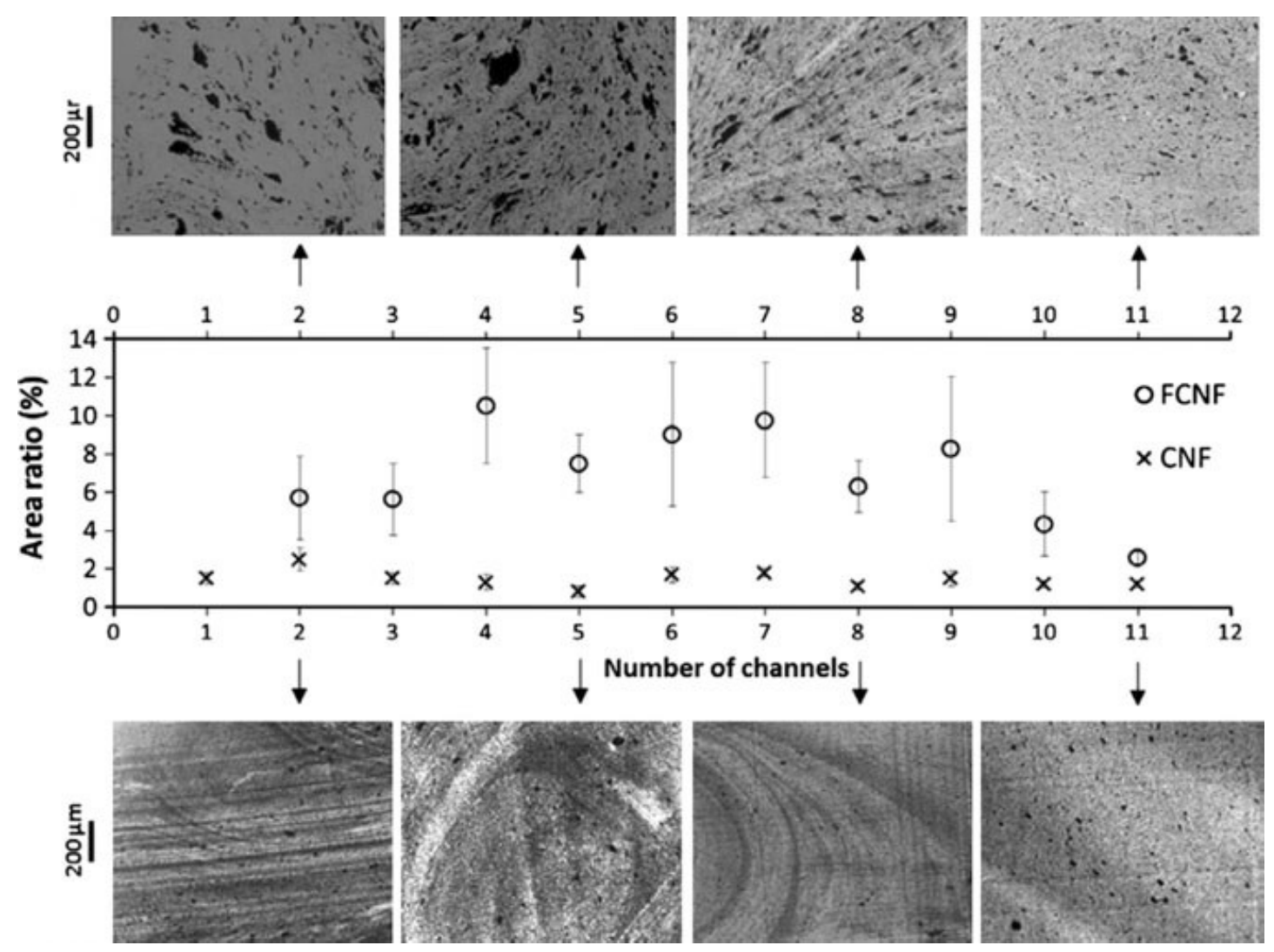

Fig. 13 Evolution of the dispersion of polypropylene/CNF composites along the length of the prototype extensional mixer, containing as-received (CNF) or functionalized (FCNF) fillers. Adapted from Novais et al. [61] 
The low molecular weight PP grafted with maleic anhydride has greater mobility relative to the high molecular weight unmodified $\mathrm{PP}$, as well as good chemical compatibility with the FCNF surface. The PP/CNF composite evidenced a relatively similar low agglomerate area ratio along the mixer, which indicates that significant filler dispersion was achieved during flow through the first converging/diverging sequence. Equivalent scanning electron microscopy micrographs (not shown) revealed that impregnation of the FCNF agglomerates was easier, resulting in the formation of PP-g-MA/FCNF clusters. However, these are not compatible with the non-polar, high molecular weight PP and, therefore, remain difficult to break into smaller fragments. The combined effect of these two factors could explain the slight increase in Area Ratio $\left(A_{R}\right)$ measured for the FCNF filler along the first part of the mixer. The subsequent gradual decrease in $A_{R}$ probably took place by erosion. Towards the exit of the mixer, sufficiently low values of $A_{R}$ will correspond to increased viscosities and so to higher hydrodynamic stresses, generating higher dispersion rates.

The body of experimental knowledge accumulated on the dispersion by melt mixing of $\mathrm{CNT}$ and $\mathrm{CNF}$ in various thermoplastic polymer matrices, using different types of equipment and processing conditions, enabled the progressive identification of various common features that were used to gradually build-up a general phenomenological dispersion model. As illustrated in Fig. 14, dispersion starts with the polymer melt wetting the agglomerates of filler and then infiltrating them, thus

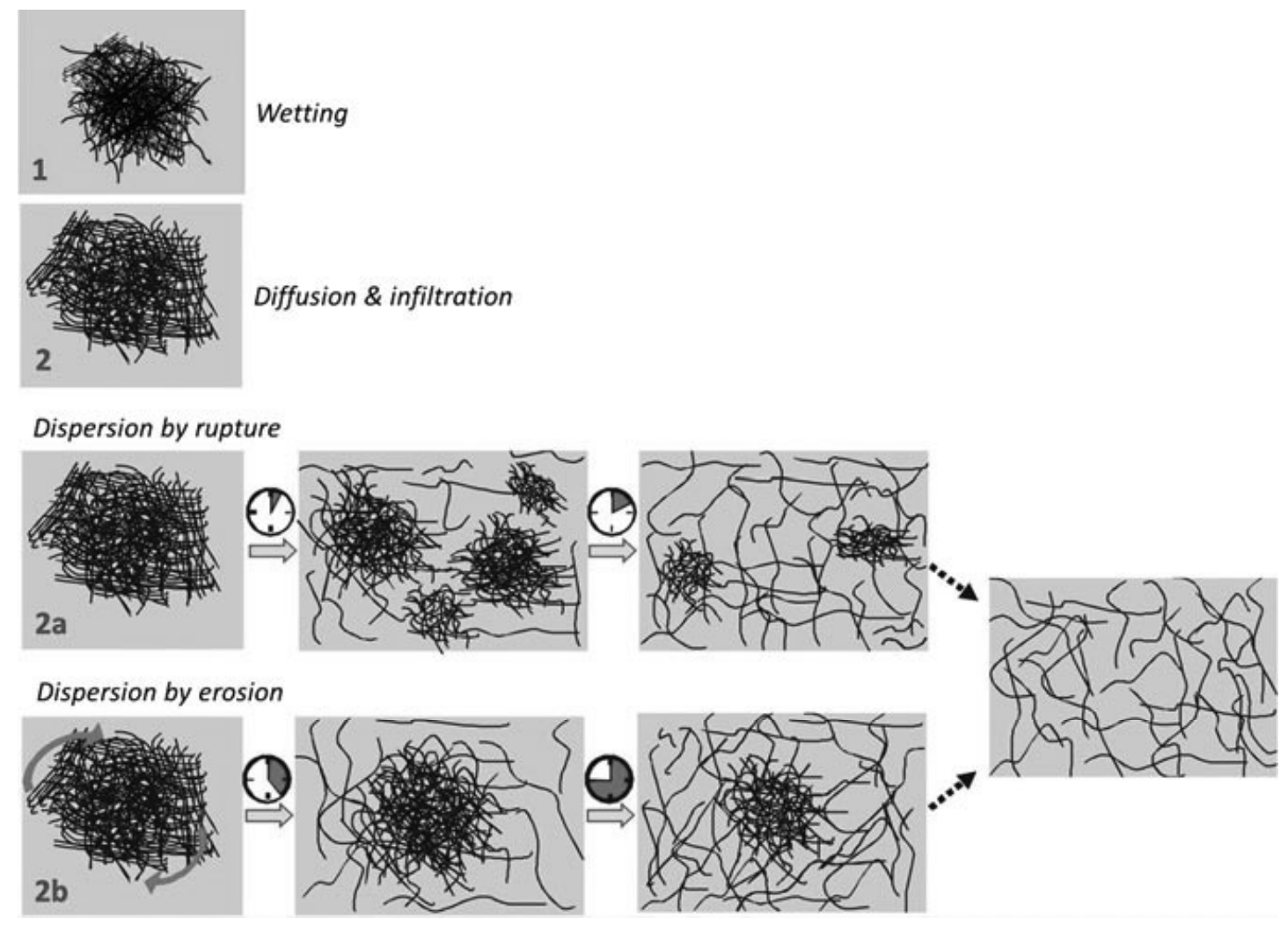

Fig. 14 Proposed general dispersion mechanism for fiber-like carbon-based fillers. Adapted from Kasaliwal et al. [40] and Sathyanarayana and Hübner [79] 
reducing their strength. The application of sufficiently intensive hydrodynamic stresses (shear/extensional) during flow will cause a decrease in the size of the initial agglomerates by rupture and/or erosion. Rupture involves the successive break-up of the agglomerates into smaller aggregates and, eventually, into the individual particles. As the name implies, erosion involves the continuous detachment of particles or small aggregates from the surface of bigger clusters.

Effective wetting of the agglomerates by the polymer melt requires a small interfacial tension. This is not problematic when the hydrophilic CNTs are to be mixed with polar polymers (such as polyamide, polycarbonate, or polyimide). In the case of non-polar polymers (for example, polyolefins), it is necessary to incorporate surface functionalities to the carbon-based fillers, as discussed in detail in a separate section of this chapter. Infiltration of the polymer melt obviously depends on the agglomerate density and size (in the two cases, the lower the better [3], as well as on local surface tension gradients [79], but it unquestionably requires good mobility of the polymer chains, i.e., low viscosity values. Viscosity and elasticity increase steadily with filler content. Even at low filler concentration, the formation of a filler-polymer chain network produces a significant change in the rheological behavior, with a transition from liquid like to solid like behavior [1]. Dispersion will only develop when the magnitude of the hydrodynamic stresses acting on the agglomerates becomes higher than their cohesive strength. Estimates of inter-tube binding forces and shear forces suggest that only at sufficiently high shear energy density complete separation of CNTs can be achieved, but the considerable energy density input may also induce unwanted fiber breakage [31]. Conversely, if the hydrodynamic stresses are small, interfacial forces become dominant, similarly to what is well-known for colloids and immiscible polymer blends (where droplet coalescence is a commonly observed phenomenon). In these systems, the balance between the two types of stresses is usually quantified by the capillary number [29, 57]. Likewise, in the case of suspensions containing clusters of solid particles, Scurati et al. [82] defined a fragmentation number ( $\mathrm{Fa}$ ), given by the ratio between the hydrodynamic stresses and the cohesive strength of the agglomerate. In the case of a specific polymer/silica particles system, it was experimentally shown that for $\mathrm{Fa}<2$ dispersion does not occur, for $2 \leq \mathrm{Fa}<5$ the agglomerates erode and that for $\mathrm{Fa} \geq 5$ rupture becomes the predominant mode of dispersion. Moreover, while rupture is a quick process, once erosion starts it continues for long times. Even for sufficiently high $\mathrm{Fa}$, there is a finite probability associated to the break-up process, which is proportional to the fractional change in the agglomerate surface area with respect to the initial surface area [26]. Again, a parallelism can be made with the time for droplet break-up for colloids and immiscible polymer blends, which decreases with increasing stresses and is greater for smaller droplets [57]. Although critical Fa have not yet been estimated for CNT or $\mathrm{CNF}$ (this is not an easy challenge, as agglomerate strength depends on the extent of infiltration which, in turn, is governed by the various factors identified above), the concept appears to be applicable to these fillers [39, 79].

A demonstration that when the applied hydrodynamic stresses are small interfacial forces become dominant is clearly given in Fig. 15 (see detailed description 


\section{Prototype \\ Extensional Mixer}
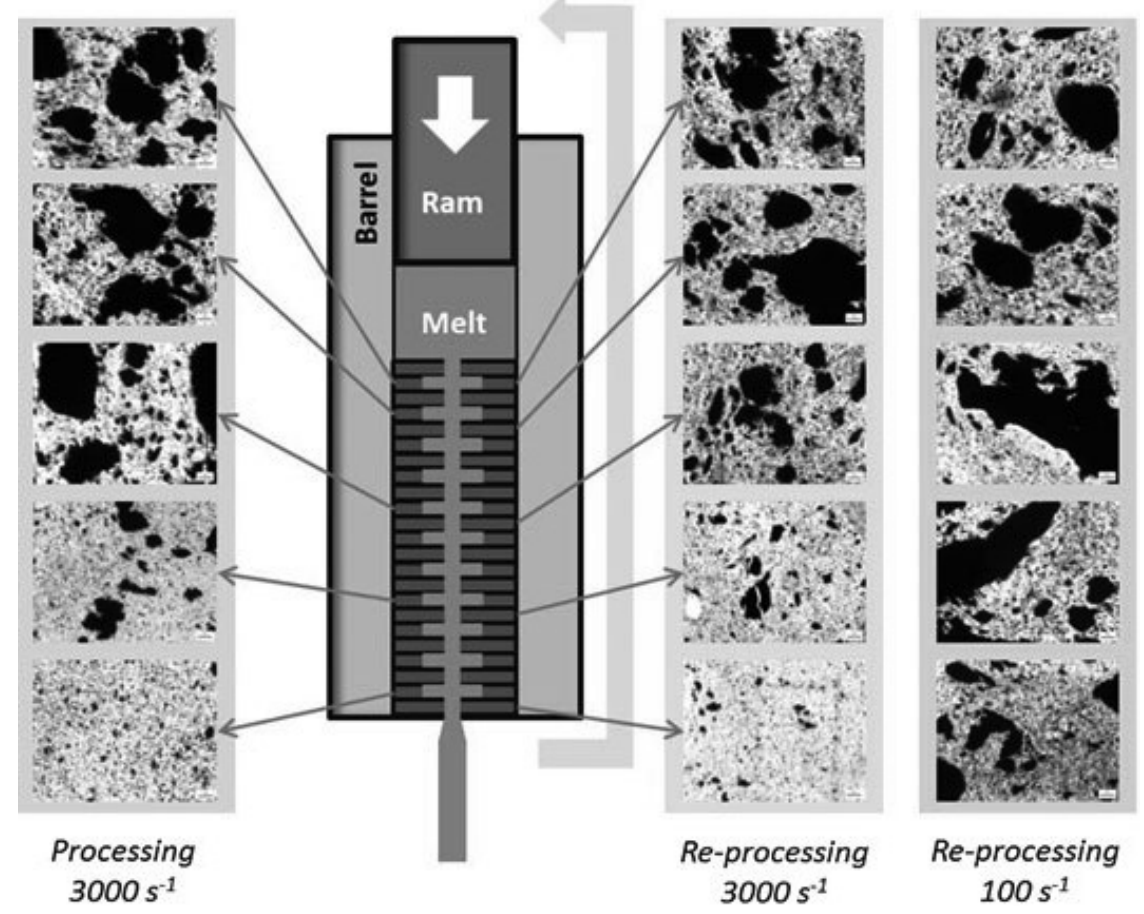

Fig. 15 Evolution of the morphology of a polypropylene/CNT nanocomposite prepared with the prototype extensional mixer at a shear rate of $3000 \mathrm{~s}^{-1}$ (left column) and then re-processed at identical (central column) and lower (right column) shear rates. Adapted from Jamali et al. [35]

and discussion in [35]. Using the prototype extensional mixer recurrently cited in this chapter, processing of a polypropylene/CNT composite was performed at $3000 \mathrm{~s}^{-1}$. As shown by the micrographs in the left column of the figure, the system achieved a fine dispersion after passing through the 12 pairs of rings that created repetitive converging/diverging flows. Once extruded and cooled down to room temperature, the material was pelletized and re-heated in the reservoir of the capillary rheometer on the bottom of which the mixer is positioned, i.e., under quiescent conditions. Then, it was reprocessed at the same shear rate. As seen in the central column of Fig. 15, the evolution of morphology upon re-processing closely mimics that of processing under identical conditions. This means that significant re-agglomeration of the CNTs took place during the re-heating stage. Remarkably, if re-processing is performed at a much lower shear rate than that used for processing (in this experiment, $100 \mathrm{~s}^{-1}$ ), dispersion becomes less efficient and the extrudate presents a coarser morphology—see right column of Fig. 15. Indeed, processing at $100 \mathrm{~s}^{-1}$ generated higher dispersion levels (not shown) than those obtained after processing at $3000 \mathrm{~s}^{-1}$ and then reprocessing at $100 \mathrm{~s}^{-1}$. Thus, it appears that re-agglomeration is a fast process during which CNTs recreate entities with high cohesive strength. In these experiments, equivalence can be made between processing and re-processing and practical industrial compounding and processing. Compounding involves high shear rates and should be able to yield fine 
morphologies, but apparently these are not stable. During processing (i.e., shaping of a product), the morphology can become coarser due to reagglomeration, the magnitude of the phenomenon depending on the operating conditions. In the same way, Alig et al. [3] reported that by thermal annealing a quiescent melt, a secondary agglomeration (or cluster formation) of nanotubes took place, with the formation of a conductive network of interconnected agglomerates. Although this last result has significant practical importance, it could not be reproduced in the experiments discussed above [35].

\section{Conclusions}

Carbon-based nanotubes and nanofibers with excellent physical properties are now synthesized at large scale and descending price. Since their discovery the scientific knowledge on these nanomaterials has been growing steadily. In contrast, the hope for immediate applications has dropped drastically along the first decade of 2000 . This "trough of disillusionment" did not affect significantly the potential markets that have been consolidating slowly but steadily.

Polymer nanocomposites incorporating CNT and CNF may be presently produced under controlled conditions and the expectations are rising again, envisaging new applications targeting at mechanical reinforcement, toughening, electrical conductivity, sensor integration, EMI shielding, and other prospects that will be presenting in the near future.

\section{References}

1. Abdel-Goad M, Potschke P (2005) Rheological characterization of melt processed polycarbonate multiwalled carbon nanotube Composites. J Non-Newton Fluid Mech 128:2-6

2. Al-Saleh MH, Sundararaj U (2009) A review of vapor grown carbon nanofiber/polymer conductive composites. Carbon 47:2-22

3. Alig I, Pötschke P, Lellinger D, Skipa T, Pegel S, Kasaliwal G, Villmow T (2012) Establishment, morphology and properties of carbon nanotube networks in polymer melts. Polymer 53:4-28

4. Anand A, Agarwal U, Rani J (2007) CNT-reinforced PET nanocomposite by melt compounding. J Appl Polym Sci 104:3090-3095

5. Arash B, Wang Q, Varadan VK (2014) Mechanical properties of carbon nanotube/polymer composites. Sci Rep 4:6479

6. Araújo RF, Silva CJ, Paiva MC, Melle-Franco M, Proença MF (2013) Efficient dispersion of multi-walled carbon nanotubes in aqueous solution by non-covalent interaction with perylene bisimides. RSC Adv 3:24535-24542

7. Baker RTK, Barber MA, Harris PS, Feates FS, Waite RJ (1972) Nucleation and growth of carbon deposits from the nickel catalyzed decomposition of acetylene. J Catal 26(1):51-62 
8. Barbas JM, Machado AV, Covas JA (2014) Processing conditions effect on dispersion evolution in a twin screw extruder: polypropylene-clay nanocomposites. Chem Eng Technol 37:1-11

9. Bauhofer W, Kovacs JZ (2009) A review and analysis of electrical percolation in carbon nanotube polymer composites. Comp Sci Technol 69:1486-1498

10. Bhattacharyya AR, Sreekumar TV, Liu T, Kumar S, Ericson LM, Hauge RH (2003) Crystallization and orientation studies in polypropylene/single wall carbon nanotube composite. Polymer 44:2373-2377

11. Bhattacharyya AR, Potschke P, Haubler L, Fischer D (2005) Reactive compatibilization of melt mixed PA6/SWNT composites: mechanical properties and morphology. Macromol Chem Phys 206:2084-2095

12. Bose S, Khare RA, Moldenaers P (2010) Assessing the strengths and weaknesses of various types of pre-treatments of carbon nanotubes on the properties of polymer/carbon nanotubes composites: a critical review. Polymer 51:975-993

13. Breuer O, Sundararaj U (2004) Big returns from small fibers: a review of polymer/carbon nanotube composites. Polym Compos 25:630-645

14. Carneiro OS, Covas JA, Reis R, Brulé B, Flat JJ (2012) The effect of processing conditions on the characteristics of electrically conductive thermoplastic composites. J Thermoplast Compos Mat 25:607-629

15. Carponcin D, Dantras E, Aridon G, Levallois F, Cadiergues L, Lacabanne C (2012) Evolution of dispersion of carbon nanotubes in Polyamide 11 matrix composites as determined by DC conductivity. Compos Sci Technol 72:515-520

16. Chen L, Pang XJ, Qu MZ, Zhang QT, Wang B, Zhang BL, Yu ZL (2006) Fabrication and characterization of polycarbonate/carbon nanotubes composites. Compos A 37:1485-1489

17. Chen J, Hamon MA, Hu H, Chen Y, Rao AM, Eklund PC, Haddon RC (1998) Solution properties of single-walled carbon nanotubes. Science 282:95-98

18. Chen J, Y-Y Shi, J-H Yang, Zhang N, Huang T, Wang Y (2013) Improving interfacial adhesion between immiscible polymers by carbon nanotubes. Polymer 54:464-471

19. Clavé G, Delport G, Roquelet C, Lauret J-S, Deleporte E, Vialla F, Langlois B, Parret R, Voisin C, Roussignol P, Jousselme B, Gloter A, Stephan O, Filoramo A, Derycke V, Campidelli S (2013) Functionalization of carbon nanotubes through polymerization in micelles: a bridge between the covalent and noncovalent methods. Chem Mater 25 (13):2700-2707

20. Coleman JN, Khan U, Blau WJ, Gun'ko YK (2006) Small but strong: a review of the mechanical properties of carbon nanotube-polymer composites. Carbon 44:1624-1652

21. Dai H (2002) Carbon nanotubes: synthesis, integration and properties. Acc Chem Res 35:1035-1044

22. Datsyuk V, Kalyva M, Papagelis K, Parthenios J, Tasis D, Siokou A, Kallitsis I, Galiotis C (2008) Chemical oxidation of multiwalled carbon nanotubes. Carbon 46:833-840

23. Davenport M (2015) Much ado about small things. Chem Eng News 93:11-15

24. De Volder MFL, Tawfick SH, Baughman RH, Hurt AJ (2013) Carbon nanotubes: present and future commercial applications. Science 339:535-539

25. Di Crescenzo A, Ettorre V, Fontana A (2014) Non-covalent and reversible functionalization of carbon nanotubes. Beilstein J Nanotechnol 5:1675-1690

26. Domingues N, Gaspar-Cunha A, Covas JA, Camesasca M, Kaufman M, Manas-Zloczower I (2010) Dynamics of filler size and spatial distribution in a plasticating single screw extruder -modeling and experimental observations. Int Polym Proc XXV:188-198

27. Ferreira T, Paiva MC, Pontes AJ (2013) Dispersion of carbon nanotubes in polyamide 6 for microinjection moulding. J Polym Res 20:301-310

28. Georgakilas V, Kordatos K, Prato M, Guldi DM, Holzinger M, Hirsch A (2002) Organic functionalization of carbon nanotubes. J Am Chem Soc 124:760-761

29. Grace HP (1982) Dispersion phenomena in high viscosity immiscible fluid systems and application of static mixers as dispersion devices in such systems. Chem Eng Commun 14:225-277 
30. Hirsch A (2002) Functionalization of single-walled carbon nanotubes. Angew Chem Int Ed 41:1853-1859

31. Huang Y-Y, Terentjev EM (2012) Dispersion of carbon nanotubes: mixing, sonication, stabilization, and composite properties. Polymers 4:275-295

32. Hwang TY, Kim HJ, Ahn Y, Lee JW (2010) Influence of twin screw extrusion processing condition on the properties of polypropylene/multi-walled carbon nanotube nanocomposites. Korea-Aus Rheol J 22:141-148

33. Iijima S (1991) Helical microtubules of graphitic carbon. Nature 354:56-58

34. Inno.CNT (2011) Innovation Alliance CNT-Carbon Nanomaterials Conquer Markets, Innovationsallianz CNT. http://www.inno-cnt.de. Accessed 22 July 2015

35. Jamali S, Paiva MC, Covas JA (2013) Dispersion and re-agglomeration phenomena during melt mixing of polypropylene with multi-wall carbon nanotubes. Polym Test 32:01-707

36. Jogi BF, Sawant M, Kulkarni M, Brahmankar PK (2012) Dispersion and performance properties of carbon nanotubes (CNTs) based polymer composites: a review. J Encapsulation Adsorpt Sci 2(69):78

37. De Jong KP, Geus JW (2000) Carbon nanofibers: catalytic synthesis and applications. Catal Rev-Sci Eng 42(4):481-5107

38. Delgado JL, de la Cruz P, Langa F, Urbina A, Casado J, Lopez-Navarrete JT (2004) Microwave-assisted sidewall functionalization of single-wall carbon nanotubes by Diels-Alder cycloaddition. Chem Commun 15:1734-1735

39. Kasaliwal GR, Pegel S, Goldel A, Potschke P, Heinrich G (2010) Analysis of agglomerate dispersion mechanism of multiwalled carbon nanotubes during melt mixing in polycarbonate. Polymer 51:2708-2720

40. Kasaliwal G, Villmow T, Pegel S, Pötschke P (2011) Influence of material and processing parameters on carbon nanotube dispersion in polymer melts. In: McNally T, Pötschke P (eds) Polymer carbon nanotube composites: preparation, properties and applications. Woodhead Publishing Limited, Cambridge, pp 92-132

41. Kohlgruber K (ed) (2008) Co-rotating twin screw extruders. Carl Hanser Verlag, Munich

42. Krause B, Petzold G, Pegel S, Pötschke P (2009) Correlation of carbon nanotube dispersability in aqueous surfactant solutions and polymers. Carbon 47:602-612

43. Krause B, Mende M, Pötschke P, Petzold G (2010) Dispersability and particle size distribution of CNTs in an aqueous surfactant dispersion as a function of ultrasonic treatment time. Carbon 48:2746-2754

44. Li Y, Yang D, Adronov A, Gao Y, Luo X, Li H (2012) Covalent functionalization of single-walled carbon nanotubes with thermoresponsive core cross-linked polymeric micelle Macromolecules 45(11):4698-4706

45. Li Y, Shimizu H (2007) High-shear processing induced homogenous dispersion of pristine multiwalled carbon nanotubes in a thermoplastic elastomer. Polymer 48:2203-2207

46. Lin TS, Cheng LY, Hsiao CC, Yang ACM (2005) Percolated network of entangled multiwalled carbon nanotubes dispersed in polystyrene thin films through surface grafting polymerization. Mat Chem Phys 94:438-443

47. Lin B, Sundararaj U, Potschke P (2006) Melt mixing of polycarbonate with multiwalled carbon nanotubes in miniature mixers. Macromol Mater Eng 291:227-238

48. Liu T, Phang IY, Shen L, Chow SY, Zhang YD (2004) Morphology and mechanical properties of MWCNT reinforced nylon-6 composites. Macromolecules 37:7214-7222

49. Ma PC, Siddiqui NA, Marom G, Kim JK (2010) Dispersion and functionalization of carbon nanotubes for polymer-based nanocomposites: a review. Compos A 41:1345-1367

50. Machado AV, Covas JA, Walet M, Van Duin M (2001) Effect of composition and processing conditions on the chemical and morphological evolution of PA-6/EPM/ EPM-g-MA blends in a corotating twin-screw extruder. J Appl Polym Sci 80:1535-1546

51. Mahfuz H, Adnan A, Rangari VK, Hasan MM, Jeelani S, Wright WJ et al (2006) Enhancement of strength and stiffness of Nylon 6 filaments through carbon nanotubes reinforcement. Appl Phys Lett 88:083119 
52. Maric M, Macosko CW (2001) Improving polymer dispersions in mini-mixers. Polym Eng Sci 41:118-130

53. MarketsandMarkets (2013) Global CNT Market-SWCNT, MWCNT, Technology, Applications, Trends \& Outlook (2011-2016)". http://www.marketsandmarkets.com/ Market-Reports/carbon-nanotubes-139.html. Accessed 15 July 2015

54. MarketsandMarkets (2014) Carbon Nanotubes (CNTs) Market by Type (SWCNTS \& MWCNTS), Application (Electronics \& Semiconductors, Chemical \& Polymers, Batteries \& Capacitors, Energy, Medical, Composites, \& Aerospace \& Defense) \& Geography - Global Trends \& Forecasts to 2018. http://www.marketsandmarkets.com/Market-Reports/carbonnanotubes-139.html. Accessed 15 July 2015

55. Micusik M, Omastova M, Krupa I, Prokes J, Pissis P, Logakis E, Pandis P, Potschke P, Pionteck (2009) A comparative study on the electrical and mechanical behaviour of multi-walled carbon nanotube composites prepared by diluting a masterbatch with various types of polypropylenes. J Appl Polym Sci 113:2536-2551

56. Menzer K, Krause B, Boldt R, Kretzschmar B, Weidisch R, Pötschke P (2011) Percolation behaviour of multiwalled carbon nanotubes of altered length and primary agglomerate morphology in melt mixed isotactic polypropylene-based composites. Compos Sci Technol 71:1936-1943

57. Manas-Zloczower I (2009) Mixing and compounding of polymers: theory and practice, 2nd edn. Hanser, Munich

58. Mayhew E, Prakash V (2014) Thermal conductivity of high performance carbon nanotube yarn-like fibers. J Appl Phys 115:174306

59. Monthioux M, Noé L, Dussault L, Dupin J-C, Latorre N, Ubieto T, Romeo E, Rovo C, Monzón A, Guimon C (2007) Texturising and structurising mechanisms of carbon nanofilaments during growth. J Mater Chem 17:4611-4618

60. Muller MT, Krause B, Kretzschmar B, Potschke P (2011) Influence of feeding conditions in twin-screw extrusion of PP/MWCNT composites on electrical and mechanical properties. Compos Sci Technol 71:1535-1542

61. Novais RM, Covas JA, Paiva MC (2012) The effect of flow type and chemical functionalization on the dispersion of carbon nanofiber agglomerates in polypropylene. Compos A 43:833-841

62. Novais RM, Simon F, Paiva MC, Covas JA (2012) The influence of carbon nanotube functionalization route on the efficiency of dispersion in polypropylene by twin-screw extrusion. Compos A 43:2189-2198

63. Novais RM, Simon F, Pötschke P, Villmow T, Covas JA, Paiva MC (2013) Poly(lactic acid) composites with poly(lactic acid)-modified carbon nanotubes. J Polym Sci Part A: Polym Chem 51:3740-3750

64. Oberlin A, Endo M, Koyama T (1976) Filamentous growth of carbon through benzene. J Crystal Growth 32(3):335-349

65. Paiva MC, Simon F, Novais RM, Ferreira T, Proença MF, Xu W, Besenbacher F (2010) Controlled functionalization of carbon nanotubes by a solvent-free multicomponent approach. ACS Nano 4(12):7379-7386

66. Paiva MC, Zhou B, Fernando KAS, Lin Y, Kennedy JM, Sun Y-P (2004) Mechanical and morphological characterization of polymer-carbon nanocomposites from functionalized carbon nanotubes. Carbon 42:2849-2854

67. Pan Y, Chan SH, Zhao J (2010) Correlation between dispersion state and electrical conductivity of MWCNTs/PP composites prepared by melt blending. Compos A 41:419-426

68. Peeterbroeck S, Alexandre M, Nagy JB, Pirlot C, Fonseca A, Moreau N et al (2004) Polymer-layered silicate-carbon nanotube nanocomposites: unique nanofiller synergistic effect. Compos Sci Technol 64:2317-2323

69. Pegel S, Pötschke P, Petzold G, Alig I, Dudkin SM, Lellinger D (2008) Dispersion, agglomeration, and network formation of multiwalled carbon nanotubes in polycarbonate melts. Polymer 49:974-984 
70. Peigney A, Laurent Ch, Flahaut E, Bacsa RR, Rousset A (2001) Specific surface area of carbon nanotubes and bundles of carbon nanotubes. Carbon 39:507-514

71. Potschke P, Pegel S, Claes M, Bonduel D (2008) A novel strategy to incorporate carbon nanotubes into thermoplastic matrices. Macromol Rapid Commun 29:244-251

72. Prasek J, Drbohlavova J, Chomoucka J, Hubalek J, Jasek O, Adam V, Kizek R (2011) Methods for carbon nanotubes synthesis - review. J Mater Chem 21:15872-15884

73. Proença MF, Araújo RF, Paiva MC, Silva CJ (2009) The Diels-Alder cycloaddition reaction in the functionalization of carbon nanofibers. J Nanosci Nanotechnol 9:6234-6238

74. Qian D, Dickey EC, Andrews R, Rantell T (2000) Load transfer and deformation mechanisms in carbon nanotube-polystyrene composites. Appl Phys Lett 76:2868-2871

75. Safadi B, Andrews R, Grulke EA (2002) Multiwalled carbon nanotube polymer composites: synthesis and characterization of thin films. J Appl Polym Sci 84:2660-2669

76. Saito R, Fujita M, Dresselhaus G, Dresselhaus M (1992) Electronic structure of graphene tubules based on $\mathrm{C}_{60}$. Phys Rev B 46(3):1804-1811

77. Saito Y, Yoshikawa T, Bandow S, Tomita M, Hayashi T (1993) Interlayer spacings in carbon nanotubes. Phys Rev B 48(3):1907-1909

78. Salzano de Luna M, Pellegrino L, Daghetta M, Mazzocchia CV, Acierno D, Filippone G (2013) Importance of the morphology and structure of the primary aggregates for the dispersibility of carbon nanotubes in polymer melts. Compos Sci Technol 85:17-22

79. Sathyanarayana S, Hübner C (2013) Thermoplastic nanocomposites with carbon nanotubes. In: Njuguna J (ed) Structural nanocomposites, perspectives for future applications. Springer, Heidelberg, pp 19-60

80. Sathyanarayana S, Olowojoba G, Weiss P, Caglar B, Pataki B, Mikonsaari I, Hübner C, Henning F (2013) Compounding of MWCNT with PS in a twin-screw extruder with varying process parameters: morphology, interfacial behaviour, thermal stability, rheology and volume resistivity. Macromol Mat Eng 298:89-105

81. Scott CE, Macosko CW (1991) Model experiments concerning morphology development during the initial stages of polymer blending. Polym Bull 26:341-348

82. Scurati A, Feke DL, Manas-Zloczower I (2005) Analysis of the kinetics of agglomerate erosion in simple shear flows. Chem Eng Sci 60:6564-6573

83. Skipa T, Lellinger D, Böhm W, Saphiannikova M, Alig I (2010) Influence of shear deformation on carbon nanotube networks in polycarbonate melts: interplay between build-up and destruction of agglomerates. Polymer 51:201-210

84. Socher R, Krause B, Boldt R, Hermasch S, Wursche R, Potschke P (2011) Melt mixed nano composites of PA12 with MWNTs: influence of MWNT and matrix properties on macrodispersion and electrical properties. Compos Sci Technol 71:306-314

85. Socher R, Krause B, Müller MT, Boldt R, Pötschke P (2012) The influence of matrix viscosity on MWCNT dispersion and electrical properties in different thermoplastic nanocomposites. Polymer 53:495-504

86. Suhr J, Koratkar NA (2008) Energy dissipation in carbon nanotube composites: a review. J Mater Sci 43:4370-4382

87. Tang W, Santare MH, Advani SG (2003) Melt processing and mechanical property characterization of multi-walled carbon nanotube high density polyethylene composite films. Carbon 41:2779-2785

88. Tasis D, Tagmatarchis N, Bianco A, Prato M (2006) Chemistry of carbon nanotubes. Chem Rev 106:1105-1136

89. Tessonnier J-P, Su DS (2011) Recent progress on the growth mechanism of carbon nanotubes: a review. ChemSusChem 4:824-847

90. Thomassin J-M, Vuluga D, Alexandre M, Jérôme C, Molenberg I, Huynen I, Detrembleur C (2012) Convenient route for the dispersion of carbon nanotubes in polymers: application to the preparation of electromagnetic interference (EMI) absorbers. Polymer 53:169-174

88. Tibbetts GG, Lake ML, Strong KL, Rice BP (2007) A review of the fabrication and properties of vapor-grown carbon nanofiber/polymer composites. Comp Sci Technol 67:1709-1718 
92. Tokihisa M, Yakemoto K, Sakai T, Utracki LA, Sepehr M, Li J, Simard Y (2006) Extensional flow mixer for polymer nanocomposites. Polym Eng Sci 41:1040-1050

93. Tu ZC, Ou-Yang ZC (2002) Single-walled and multiwalled carbon nanotubes viewed as elastic tubes with the effective Young's moduli dependent on layer number. Phys Rev B 65:233407

94. Villmow T, Potschke P, Pegel S, Haussler L, Kretzschmar B (2008) Influence of twin-screw extrusion conditions on the dispersion of multi-walled carbon nanotubes in a poly(lactic acid) matrix. Polymer 49:3500-3509

95. Wagner HD (2002) Nanotube-polymer adhesion: a mechanics approach. Chem Phys Lett 361:57-61

96. Wichmann MHG, Schulte K, Wagner HD (1998) On nanocomposite toughness. Compos Sci Technol 68 (1):329-331

97. Winey KI, Vaia RA (2007) Polymer nanocomposites. MRS Bull 32(4):314-322

98. Wu TM, Chen EC (2008) Preparation and characterization of conductive carbon nanotube-polystyrene nanocomposites using latex technology. Comp Sci Technol 68:2254-2259

99. Xia H, Wang Q, Qiu G (2003) Polymer encapsulated CNTs prepared through ultrasonically initiated in situ emulsion polymerization. Chem Mater 15:3879-3886

100. Yang BX, Pramoda KP, Xu GQ, Goh SH (2007) Mechanical reinforcement of polyethylene using polyethylene-grafted multiwalled carbon nanotubes. Adv Funct Mater 17:2062-2069

101. Zhang WD, Shen L, Phang IY, Liu T (2004) CNT reinforced nylon-6 composite prepared by simple melt compounding. Macromolecules 37:256-259

102. Zou Y, Feng Y, Wang L, Liu X (2004) Processing and properties of MWNT/HDPE composites. Carbon 42:271-277 